\title{
Building Information Modeling-Based Building Energy Modeling: Investigation of Interoperability and Simulation Results
}

\author{
Mohamed H. Elnabawi ${ }^{1,2,3 *}$ \\ ${ }^{1}$ College of Engineering, Applied Science University (ASU) (In Partnership With London South Bank University), Eker, Bahrain, \\ ${ }^{2}$ Architectural Systems Engineering (ASE) Department, Faculty of Engineering, October University for Modern Sciences and \\ Arts (MSA), Cairo, Egypt, ${ }^{3}$ The Faculty of Engineering, October University for Modern Sciences and Arts (MSA), Cairo, Egypt
}

\section{OPEN ACCESS}

Edited by:

Bao-Jie He,

University of New South

Wales, Australia

Reviewed by:

Amir Mahdiyar,

University of Science

Malaysia, Malaysia

Assed Haddad

Federal University of Rio de Janeiro, Brazil

*Correspondence: Mohamed H. Elnabaw melnabawi@aucegypt.edu; mmahgoub@msa.eun.eg

Specialty section

This article was submitted to Sustainable Design and Construction,

a section of the journal

Frontiers in Built Environment

Received: 28 July 2020 Accepted: 19 October 2020 Published: 03 December 2020

Citation:

Elnabawi MH (2020) Building Information Modeling-Based Building

Energy Modeling: Investigation of Interoperability and Simulation

Results.

Front. Built Environ. 6:573971. doi: 10.3389/fbuil.2020.573971
There is increasing need to apply building information modeling (BIM) to low energy buildings, this includes building energy modeling (BEM). If a building energy model can be flawlessly generated from a BIM model, the energy simulation process can be better integrated within the design, can be more competent, and timesaving. However, concerns about both the reliability and integrity of the data transfer process and the interoperability between the BIM and BEM prevent any implementation of BIMbased energy modeling on a large scale. This study addresses the accuracy and integrity of BIM-based energy modeling by investigating how well Autodesk's Revit (BIM), in conjunction with two of the most used energy modeling programs (BEM) known as DesignBuilder and Virtual Environment (IES-ve), were integrated in terms of interoperability, including location and weather files, geometry, construction and materials, thermal zones, occupancy operating schedules, and HVAC systems. All misrepresented data during the interoperability process were identified, followed by benchmarking between the BIM-based energy modeling simulation outcomes and the actual energy consumption of the case study, to assess the reliability of the process. The investigation has revealed a number of interoperability issues regarding the BIM data input and BEM data interpretation. Overall, BIM-based energy modeling proved to be a promising tool for sustainable and low energy building design, however, the BIM to BEM process is a non-standardized method of producing building energy models as it varies from one modeler to another, and the BIM to BEM process. All these might slow down any possible application for the process and might cause some uncertainties for the professionals in the field applying it.

\footnotetext{
Keywords: interoperability, building information modeling (BIM), building energy modeling (BEM), building \& sustaining a research program, energy consumption (EC)
}

\section{INTRODUCTION}

Energy use in buildings is a major contributor to energy consumption due to population increases, housing stock, and better living standards, and this leads to an expected increase in energy use. According to the international energy agency (IEA, 2019), global energy demand rose by $2.3 \%$ in 2018, and is considered to be the fastest growth in the last decade. This energy demand can be 
tackled by the effective use of energy within a built-up environment, by applying low energy designs and sustainable techniques. Such an approach explains the growing demand for the application of building information modeling (BIM) for sustainable design, including building energy modeling (BEM) within the architecture, engineering, and construction (AEC) industries.

While BIM tolerates performance assessment at earlier building stages, such as orientation, the location of material properties, and window to wall ratio (Chen et al., 2017; Gao et al., 2019), BEM software tools professionally evaluate building performance in more advanced stages (Jin et al., 2019). Accordingly, coupling the two models can reduce the effort and time consumed in generating model geometry and, by assigning building parameters in the BIM-based BEM model, the data exchange and information reliability can be maintained (Chen et al., 2018). However, existing barriers concerning the lack of availability of an adequate framework for data exchange, as well as interoperability, means that the materials or data from the BIM for BEM are lacking. According to Forth et al. (2019), the data input preparations usually have significant errors and costs, such as with the structure geometry and material properties. Moreover, from the architect and designer standpoint, most of the available BEM tools are either non-supportive as a design tool or complicated in the design needs (Gratia and De Herde, 2002; van Dijk and Luscuere, 2002; Attia and De Herde, 2009; Won and Cheng, 2017; Bertin et al., 2020). In this respect, BIM and BEM remain separate and segregated, even though they have been extensively used in their respective fields. Until recently, more consideration has been given to the integration of BIM between the various disciplines, by providing a single $3 \mathrm{D}$ CAD model containing all appropriate data which can be simply exported to different function-specific software (Eastman et al., 2008). This increases BEM efficiency in facilitating its data input by having more scenarios to analyze (Maile et al., 2007; Gao et al., 2019). The data associated with a BIM file can be easily exported as input for the BEM file, to reduce the degree of complexity and amount of time consumed in re-drawing the model and adjusting the simulation settings on BEM (Laine et al., 2007; Gao et al., 2019; Sarvari et al., 2020).

Previous studies, however, have reported that some variation still exists with the interoperability level between the existing BEM and BIM, in addition to some data input and amendments being misrepresented during the data exchanging process from BIM to BEM (Ostergard et al., 2016). However, recently, there have been some new developments in the methods of data transfer between BIM and BEM from BEM developers, such as DesignBuilder and Virtual Environment (IES VE, 2011), the only BEM tools on the market which created their own plug-ins as a way for facilitating the data transfer from Revit. Accordingly, the paper aims to assess the most identified areas of interoperability including the quality of data transfer between the BIM and BEM models as recommended by Cemesova et al. (2015) and Gao et al. (2019). These areas include: (a) location and geometry; (b) construction and space; (c) thermal zones; (d) occupancy, equipment, and lighting loads; (e) HVAC systems; and, (f) energy simulation. This is in addition to outcomes validation to ensure the accuracy of the whole process. In this respect, a data exchange from Revit, as BIM, into DesignBuilder and Virtual Environment (IES VE, 2011) as two different BEM tools, were conducted for a typical residential building. All the above-mentioned areas were analyzed and the software outcomes were examined against the actual energy consumption measurement for the validity and efficiency of the process.

\section{Review of Interoperability}

There is increasing demand for interoperability between multiple models and tools, especially within the architecture, engineering, and construction (AEC) fields. Interoperability has been defined in several studies. According to IEEE STD 610.12, it is the ability of two or more systems or components to exchange and use information (IEEE STD 610.12) (Standard 90 Standards Coordinating Committee, 1990). According to Eastman et al. (2008), interoperability is the ability to exchange data between applications flawlessly, to achieve a smooth workflow in which the models' transaction is automated. This unified data exchange should avoid any possible human error and data repetition, and accelerate the reproduction of the model (Eastman et al., 2008; Cemesova, 2013). Another definition describes interoperability as the ability to ensure that data generated by any tool can be appropriately interpreted by all other tools (Shen et al., 2010; BIEG, 2020). Any misperception or misconnection among the participating tools can result in interoperability subjects (Bahar et al., 2013). Therefore, the interoperability issues that arise between software result in inconsistent and fragmented data that prohibit the automatic flow of information from one tool to another. Moreover, interoperability should also permit bidirectional updates and the exchange of data for building information; in other words, any modification in one of the tools involved in the interchanging process should stream between the programs (Kumar, 2008; Moon et al., 2011). However, the only possible flow of information is one way, despite the exchange format being used (Eastman et al., 2008; Kumar, 2008; Moon et al., 2011).

Interoperability, for a long time, has been limited to geometry exchange using a file-based format, such as DXF and IGES, until the $80 \mathrm{~s}$, and with the emerging needs for exchanging semantic data, new formats have been developed to secure the data and object model exchange between the different fields. Regarding the BIM and BEM, the IFC (Industry Foundation Class) and gbXML (Green Building XML-XML is an eXtensible Markup Language) are considered the most common data schema responsible for the data exchange process within the industry (Fernald et al., 2018). Each format has its pros and cons, however. Both formats were developed to enable the interoperability among different software environments and can be kept up to date for the duration of the lifecycle of a building (Dong et al., 2007; Eastman et al., 2008; Hitchcock and Wong, 2011; Moon et al., 2011; Ramaji et al., 2020). Despite the developments of all these file formats, unsuccessful data exchange between BIM and BEM remains one of the main issues preventing the extensive application of BIM-based analysis (Moon et al., 2011; Bynum et al., 2013; El Asmi et al., 2015). Thus far, there is no common framework or methodology for transferring information between BIM and $\mathrm{BEM}$, and any attempt to make such a transfer is strongly linked to the experience of the expert (Chen et al., 2018). This has 
left the field with haphazard rules and methods developed over time by certain individuals (Bazjanac, 2008, 2018; Hitchcock and Wong, 2011; Elnabawi and Hamza, 2019). Accordingly, the BIM to BEM process is inconsistent and lacks any standardization, in that BEM energy modeling results vary from one expert to another, even if they all shared the same initial building design data (Maile et al., 2007; Bazjanac, 2008; Hitchcock and Wong, 2011; Bahar et al., 2013; Cemesova, 2013; El Asmi et al., 2015). Furthermore, there is ambiguity and uncertainty regarding the interoperability between BIM and BEM tools, as some critical information may be lost or misinterpreted during the process (Dong et al., 2007; Moon et al., 2011; Gourlis and Kovacic, 2017; Han et al., 2018; Solmaz, 2019). As emphasized by USGSA (2015), several BEM tools disregard construction and mechanical information, or lack the competence to verify the integrity of the model and completeness after being imported; these interoperability issues usually take place during certain phases of the process including, mapping data to the BIM file under certain file standards such as IFC or gbXML, mapping BIM data to a readable file for the BEM tool, and mapping data to the simulation engine (Kamel and Memari, 2019), which can lead to deceptive energy modeling results (Stumpf et al., 2011; Chen et al., 2018). Therefore, any attempt to standardize the data exchange process and its mechanism will significantly save time, reduce errors, and lead to overall process improvements (Hitchcock and Wong, 2011; Kamel and Memari, 2019).

\section{Interoperability Review of the Most Related Building Energy Modeling Tools}

There is a growing number of energy simulation programs available on the market currently (IBPSA, 2019). According to the Building Energy Software Tools Directory there might be more than four hundred tools as provided by the U.S. DOE in 2017. Some of these programs are commercial while others are opensource. However, only very few of these tools are used in the industry and research. Accordingly and based on comprehensive reviews including Attia et al. (2012a) and Dubois and Horvat (2012), in addition to recent publications for scholars such as Chen et al. (2018), Fernald et al. (2018), Kamel and Memari (2019), and Solmaz (2019), regarding the recent trends in the industry, a short list of the most common BEM tools among all the reviewed papers has been created for further analysis and reviews based on the following criteria adopted by Solmaz (2019):

- The general properties of the programs such as the major capabilities, programming language/platform, license, developer/company.

- Tool integrated design stage, simulation engine, interoperability/data exchange, performance criteria, applications/functions.

- Main strengths and limitations, input and output file formats, weather data and validation.

The review is also limited to programs that provide the functionalities of the BIM-based data import method, including Industry Foundation Classes (IFC)-based methods and Green
Building XML (gbXML)-based methods, as the most common building information exchange schemas (Bahar et al., 2013; Fernald et al., 2018; Kamel and Memari, 2019). IFC is object oriented with a top-down structure, and all information is illustrated in an organized approach, whilst gbXML is a bottomup structure and is easy to comprehend. Compared to IFC, gbXML proved to be more suitable for energy modeling among scholars and within the industry (Dong et al., 2007; Cheng and Das, 2014; Gao et al., 2019). First of all, gbXML is more comprehensive than IFC when it comes to energy modeling where it is capable of transferring the required data such as weather data and ventilation (Cheng and Das, 2014). Secondly, IFC identifies spaces similar to that of an architectural model rather than an energy model, therefore it considers the thickness of the elements, while the fact is energy modeling only considers the thermal properties of virtual thickness as numerical figures. Thirdly, gbXML was developed by Autodesk therefore it has been widely integrated within CAD tools and another engineering programs (Kim et al., 2015). It has been estimated that there are almost five times as many energy modeling programs which support data transferring to gbXML than the ones that support the IFC format (BuildingSMART, 2016). Overall, gbXML is better at recognizing the drawing units, building components, locations, and building type (Osello et al., 2011; Gao et al., 2019). Furthermore, when it comes to BIM-based BEM, gbXML was proven to have better performance than IFC (Gao et al., 2019).

\section{Software Selection}

Autodesk Revit is a commercially available Computer Aided Design (CAD) software that enables the user to follow a BIM workflow for any AEC project. Revit was chosen both because of its widespread application within the construction industry (AEC, 2013; Kurul et al., 2013) and the fact that it is among the leading BIM software platforms in several academic studies (Ceranic et al., 2015; Garcia and Zhu, 2015; Han et al., 2018). Based on the National Building Specification (NBS) in 2014 (NBS, 2014) and 2016 (NBS, 2016), as well as a similar survey conducted in Canada by the IBC in 2013 (IBC, 2013), Revit is the most used tool in the UK and Canada followed by a Computed Aided Design tool (CAD). It includes, among other features, producing $3 \mathrm{D}$ geometry and an energy analysis of the building. The energy simulation is conducted using Autodesk Insight 360 as a Revit plug-in. Autodesk Insight provides whole building energy, heating, cooling, day lighting, and a solar radiation simulation, utilizing the EnergyPlus simulation engine (Penttilä, 2006). The BIM practice using Autodesk Revit 2017 is confirmed as one of the best procedures for addressing the energy analysis of buildings (Kota et al., 2014).

Based on the most used BEM tools review summarized in Table 1, DesignBuilder was the tool most able to fulfill the performance criteria and application, followed by Virtual Environment. In addition to their ability to import and export in the gbXML file format (Solmaz, 2019), they are the only BEM tools which claimed to be able to create some improvements to facilitate the data exchange from Revit through creating their own Revit plug-ins. This plug-in according to the vendors should eliminate all the difficulties reported by 
TABLE 1 | Comparison of selected BEM tools (Han et al., 2018; Solmaz, 2019).

\begin{tabular}{|c|c|c|c|c|c|c|c|c|c|c|c|c|c|c|c|c|c|}
\hline \multirow[t]{2}{*}{ BEM tools } & \multirow[t]{2}{*}{ Major capabilities } & \multirow{2}{*}{$\begin{array}{l}\text { Simulation } \\
\text { engine }\end{array}$} & \multirow[t]{2}{*}{ Input data } & \multirow[t]{2}{*}{ Output data } & \multicolumn{9}{|c|}{ Performance criteria } & \multicolumn{4}{|c|}{ Application } \\
\hline & & & & & $\begin{array}{l}\text { के } \\
\text { के } \\
\text { w }\end{array}$ & 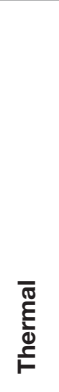 & 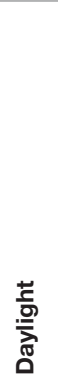 & 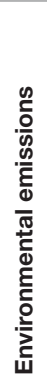 & 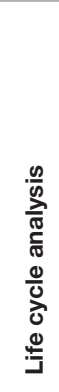 & 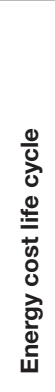 & $\begin{array}{l}\frac{\infty}{n} \\
\frac{2}{\overline{0}} \\
\frac{10}{10} \\
0 \\
0 \\
0\end{array}$ & 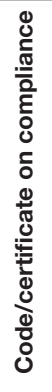 & 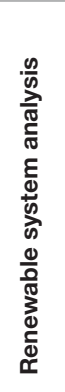 & 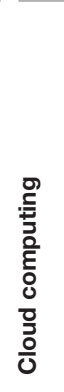 & 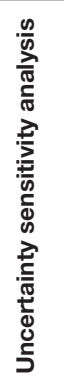 & 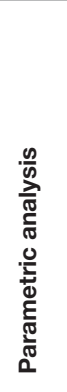 & 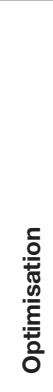 \\
\hline DesignBuilder & $\begin{array}{l}\text { - Whole building energy simulations } \\
\text { - Load calculations HVAC system } \\
\text { - selection and sizing } \\
\text { - Parametric and optimization } \\
\text { - Rating simulation } \\
\text { - Code compliance checking }\end{array}$ & $\begin{array}{l}\text { EnergyPlus/ } \\
\text { Radiance }\end{array}$ & $\begin{array}{l}\text { gbXML, .dxf, .pdf, } \\
\text {.bmp, .jpg }\end{array}$ & $\begin{array}{l}\text { CAD:AutoCAD, } \\
\text { Microstatio, } \\
\text { SketchUp using } \\
\text { 3-D dxf, .epw, } \\
\text {.csv, .tmy, .tmy2 }\end{array}$ & $\checkmark$ & $\checkmark$ & $\checkmark$ & $\checkmark$ & & $\checkmark$ & $\checkmark$ & $\checkmark$ & & $\checkmark$ & $\checkmark$ & $\checkmark$ & $\checkmark$ \\
\hline EDSL-TAS & $\begin{array}{l}\text { - Whole building energy simulations } \\
\text { - HVAC system selection and sizing } \\
\text { - Parametrics and optimization } \\
\text { - Lighting simulation } \\
\text { - Airflow simulation } \\
\text { - Code compliance checking } \\
\text { - Detailed cost analysis }\end{array}$ & self & $. g b X M L, . d w g$ & .TSD & $\checkmark$ & $\checkmark$ & $\checkmark$ & $\checkmark$ & & $\checkmark$ & $\checkmark$ & & $\checkmark$ & & & $\checkmark$ & $\checkmark$ \\
\hline EnergyPlus & $\begin{array}{l}\text { - Whole building energy simulations } \\
\text { - Load calculations } \\
\text { - HVAC system selection and sizing } \\
\text { - Lighting simulation } \\
\text { - Air flow simulation } \\
\text { - Code compliance checking }\end{array}$ & self & ifc, gbXML, text & ASCII & $\checkmark$ & $\checkmark$ & & $\checkmark$ & & & & & & & & & \\
\hline eQUEST & -Whole building energy simulations & DOE 2.2 & $g b X M L, . d w g, d x f$ & dxf, gbXML, .xls & $\checkmark$ & & & & & $\checkmark$ & & $\checkmark$ & & & & & \\
\hline $\begin{array}{l}\text { Green Building } \\
\text { Studio (GBS) }\end{array}$ & $\begin{array}{l}\text { - Whole building energy simulations } \\
\text { - Parametrics and optimization } \\
\text { - Energy conservation measures }\end{array}$ & $\begin{array}{l}\text { DOE } \\
\text { 2.2/EnergyPlus }\end{array}$ & $\begin{array}{l}\text { gbXMLenabled } \\
\text { BIM or 3D-CAD }\end{array}$ & gbXML, VRML & $\checkmark$ & & $\checkmark$ & $\checkmark$ & & & & $\checkmark$ & & $\checkmark$ & & & \\
\hline $\begin{array}{l}\text { IES-Virtual } \\
\text { Environment } \\
\text { (IES-VE) }\end{array}$ & $\begin{array}{l}\text { - Whole building energy simulations } \\
\text { - Load calculations } \\
\text { - HVAC systems selection and sizing } \\
\text { - Lighting simulation } \\
\text { - Code compliance checking }\end{array}$ & $\begin{array}{l}\text { Self \& Radiance } \\
\text { IES }\end{array}$ & $g b X M L, . d x f, . d w g$ & & $\checkmark$ & $\checkmark$ & $\checkmark$ & $\checkmark$ & $\checkmark$ & $\checkmark$ & $\checkmark$ & & & & & $\checkmark$ & $\checkmark$ \\
\hline OpenStudio & $\begin{array}{l}\text { - Whole building energy simulations } \\
\text { - Energy conservation measures } \\
\text { - Lighting simulation }\end{array}$ & $\begin{array}{l}\text { EnergyPlus/ } \\
\text { Radiance }\end{array}$ & $. g b X M L \& . I F C$ &. osm \& .IDF & $\checkmark$ & $\checkmark$ & $\checkmark$ & $\checkmark$ & & $\checkmark$ & & & & $\checkmark$ & $\checkmark$ & $\checkmark$ & \\
\hline
\end{tabular}


TABLE 2 | Interoperability tasks under investigation.

\begin{tabular}{ll}
\hline $\begin{array}{l}\text { Interoperability } \\
\text { tasks }\end{array}$ & Description \\
\hline Location & $\begin{array}{l}\text { The site location of the project } \\
\text { Building orientation } \\
\text { Weather file }\end{array}$ \\
Weather file & $\begin{array}{l}\text { Building form, spaces, and dimensions } \\
\text { Geometry }\end{array}$ \\
Construction & $\begin{array}{l}\text { Building envelope materials and thermal } \\
\text { properties }\end{array}$ \\
Thermal zone & Zone vs. Space vs. Room \\
Occupancy, & The occupant density and behavior patterns \\
equipment, and & Lighting usage \\
lighting & \\
HVAC & HVAC settings
\end{tabular}

different users of Revit gbXML export procedures, which still cause errors in the exchange of data between the BIM and BEM, and need to be addressed before modeling, as six out of ten gbXML files were successfully exported to BEM (Hitchcock and Wong, 2011; Moon et al., 2011; Salmon, 2013; Elnabawi and Hamza, 2019). According to the DesignBuilder v5.5 tutorial (DesignBuilder Revit-gbXML Tutorial, 2019), the plugin simplifies and automates the process, so in general it is best to use it.

DesignBuilder is a commercially available CAD software for $3 \mathrm{D}$ building modeling for the purpose of energy efficient design and building operation. It is considered the most comprehensive interface for EnergyPlus compared to others (Maile et al., 2007). Integrated Environmental Solution's Virtual Environment (IES VE, 2011) is a commercial software as well. Its analysis includes thermal and comfort solutions, daylighting, solar studies, egression, and carbon emissions code compliance (Leaman et al., 2007). VE uses its own simulation engine APACHESIM without allowing users any type of access to the simulation input source file for a possible inspection or manual modification. Both program's capabilities, performance criteria, and application are mentioned in Table 1.

\section{METHODOLOGY}

The study provides a special reflection on the reliability of building data transformation between BEM and BIM for the building energy simulation process, therefore the methodology was designed on two aspects which could serve the study as concluded from the literature review:

- First, assessing the accuracy of the data being imported from the BIM (AutoDesk Revit) to BEM tool, including DesignBuilder and IES-ve, through evaluating the following interoperability issues (Bahar et al., 2013; Gao et al., 2019) as presented in Table 2:

a) location and weather file

b) geometry

c) construction and materials d) thermal zones

e) occupancy operating schedule

f) HVAC systems.

- Second, determining the accuracy of DesignBuilder and IES-ve to obtain an energy performance test on the BIM-based model.

As stated in Figure 1 below, the initial stage is to identify and model a typical case study geometry, including its typology, characteristics, and all the associated data, as required in Revit, before it is exported with all the attached data to DesignBuilder and IES-ve. This is followed by step three, which is the investigation of the accuracy and type of data being transferred and interpreted. Before performing energy modeling for the representative case study as a final step using DesignBuilder and IES-ve, the energy modeling data can then be compared with the actual energy usage of the building.

\section{Case Study Selection}

The reference case study for the research is a prototype residential apartment located in a hot, arid climate. The reasons behind selecting this case study include:

- The existing level of complexity, which includes all the investigated issues regarding the exchange of data between the BIM and BEM, and which in turn serves the main aim of the study;

- The rectangular form of the building should support the flawless geometric data transfer using the gbXML format, since it only accepts rectangular forms (Gourlis and Kovacic, 2017; Gao et al., 2019) and this makes the gbXML more comprehensive in terms of transferring data related to energy simulation (Cheng and Das, 2014), which will assist in obtaining an energy performance test as one of the study aims;

- The availability of the data from a previous study by Attia et al. (2012b), which investigated occupant behavior, operational schedule, energy consumption rate, and building description. This will support one of the aims of the study to have more realistic results for validation.

\section{Modeling Approach and Settings}

Following the ideal workflow for BEM tools recommended by Maile et al. (2007) (Figure 2), the building model was simplified and the inside spaces and zones identified and labeled in BIM using Revit 2019. The location was also identified and the weather file uploaded in Revit, along with all the other required information to set up a dynamic energy simulation model, such as construction materials, HVAC system, operation schedule, and internal loads. The comprehensive model is then exported from Revit as the gbXML format, which acts as a neutral format and allows the BEM programs to import and read the file with all the associate data.

\section{Building Description}

The case study building, as shown in Figure 3, has a total area of $122 \mathrm{~m}^{2}$ with a net conditioned area of $60 \mathrm{~m}^{2}$, representing three rooms per apartment. The typology of the apartment consists of three zones, including bedrooms, a living room, 


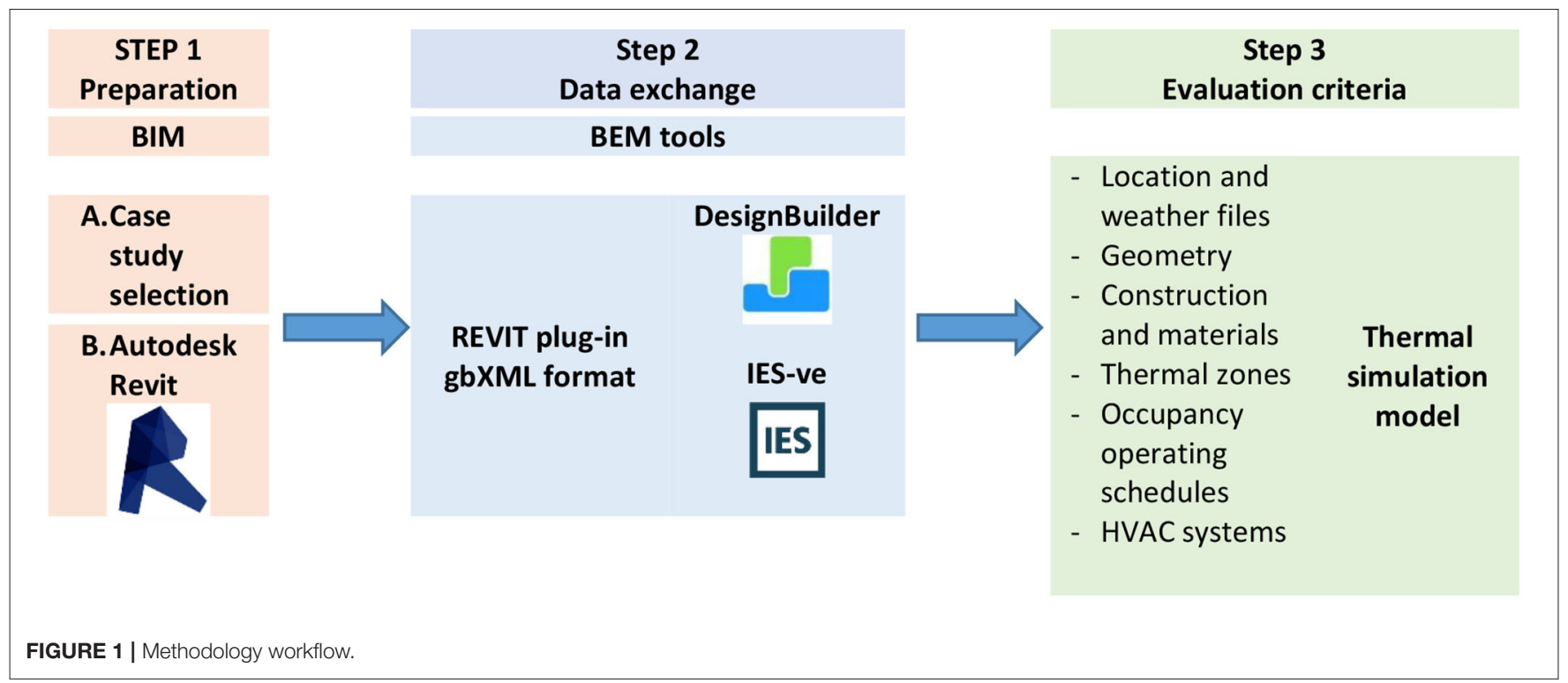

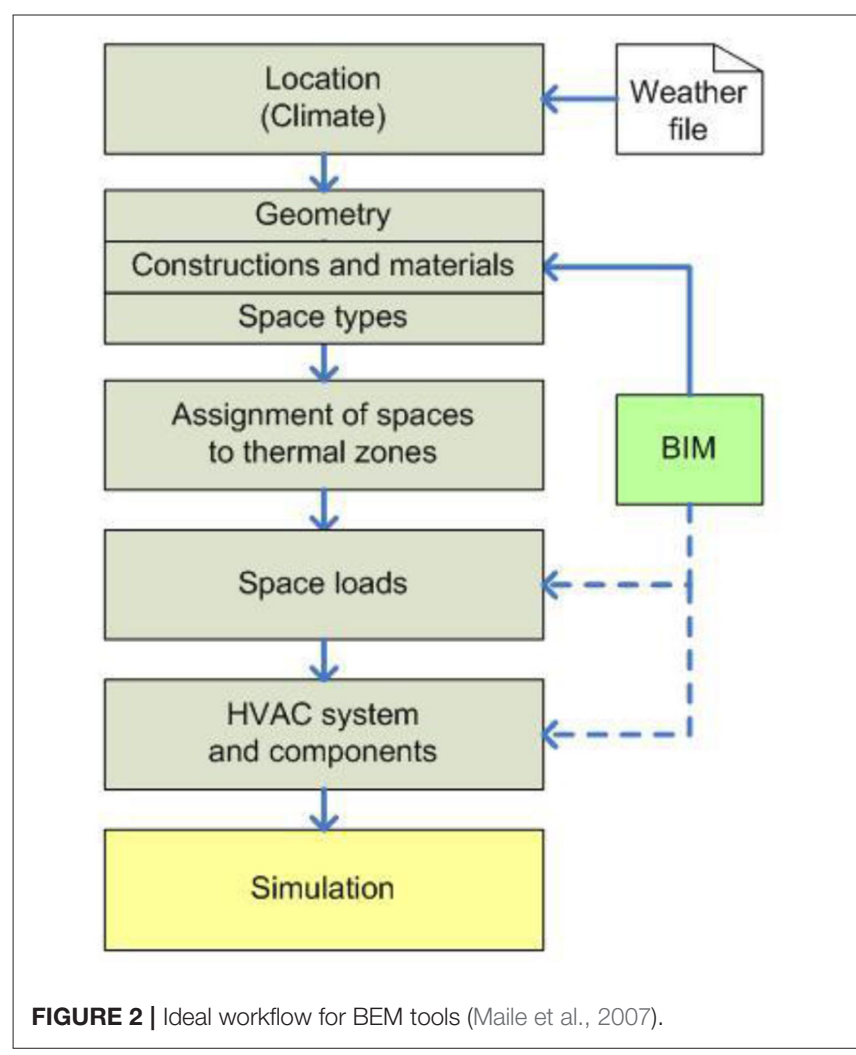

and service zones (kitchen, corridors, and bathroom). The basic building construction is a reinforced-concrete post and beam structure with $0.165 \mathrm{~m}$ thick brick infill walls without insulation or an airtight building envelope. Windows are single glazed, transparent, and have $0.003 \mathrm{~m}$ thick glass panes. The total amount of glass in the north and south facades is estimated to be between 45 and $35 \%$ of the total wall area,

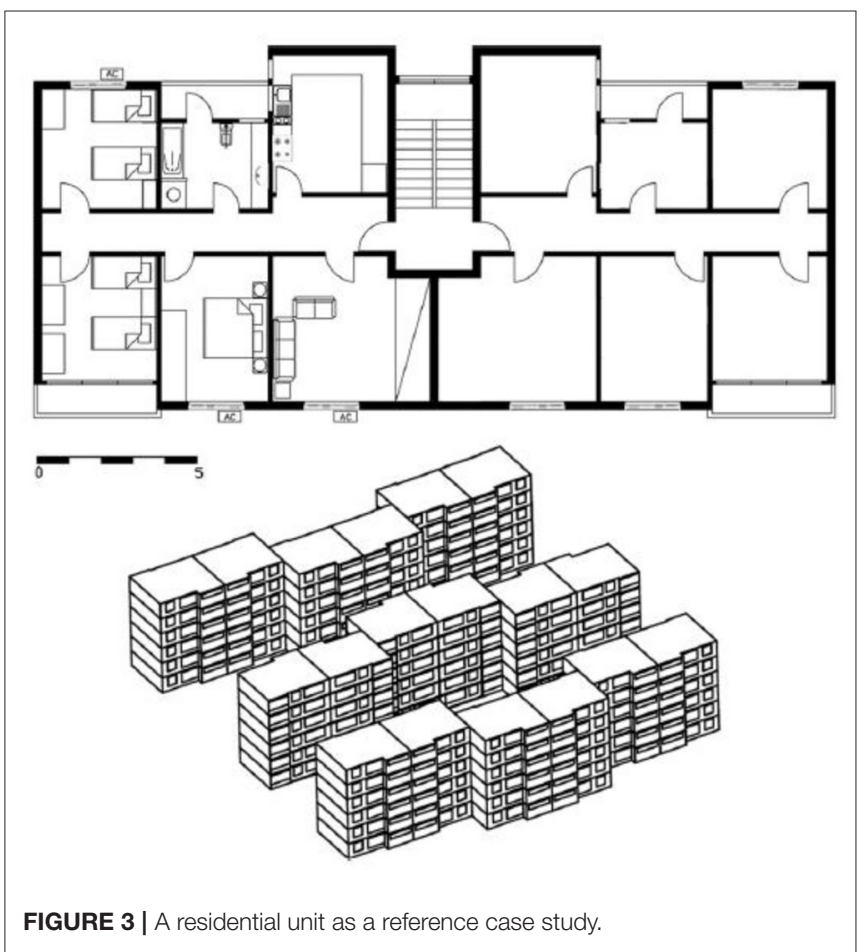

and there are no openings in the east and west directions. There is no solar protection for the facades and most wooden windows are drafty. Table 3 lists the general description of the sample building and certain properties of the construction materials used.

\section{Annual Electricity Usage}

Based on an analysis of the billing history of the local electricity utility company for the case study, Figure 4 presents the actual 
TABLE 3 | Building description.

\begin{tabular}{ll}
\hline $\begin{array}{l}\text { Building description } \\
\text { Shape }\end{array}$ & Rectangular $(25 \times 11 \times 18 \mathrm{~m})$ \\
No. of floors & 6 and $2.8 \mathrm{~m}$ height per floor \\
Aspect ratio & $2.3 / 1$ \\
Apartment description & \\
Volume & $366 \mathrm{~m}^{3}$ \\
External wall area & $110 \mathrm{~m}^{2}$ \\
Roof area & $122 \mathrm{~m}^{2}$ \\
Floor area & $122 \mathrm{~m}^{2}$ \\
Windows area & $60 \mathrm{~m}^{2}$ \\
Glazing U-value & $6.25 \mathrm{~W} / \mathrm{m}^{2} \mathrm{~K}$ \\
Exterior wall U-value & $2.5 \mathrm{~W} / \mathrm{m}^{2} \mathrm{~K}$ \\
Roof U-value & $1.39 \mathrm{~W} / \mathrm{m}^{2} \mathrm{~K}$ \\
Floor U-value & $1.58 \mathrm{~W} / \mathrm{m}^{2} \mathrm{~K}$ \\
Single clear glazing & $T v=0.88$ \\
Solar heat gain coefficient (SHGC) & 0.75
\end{tabular}

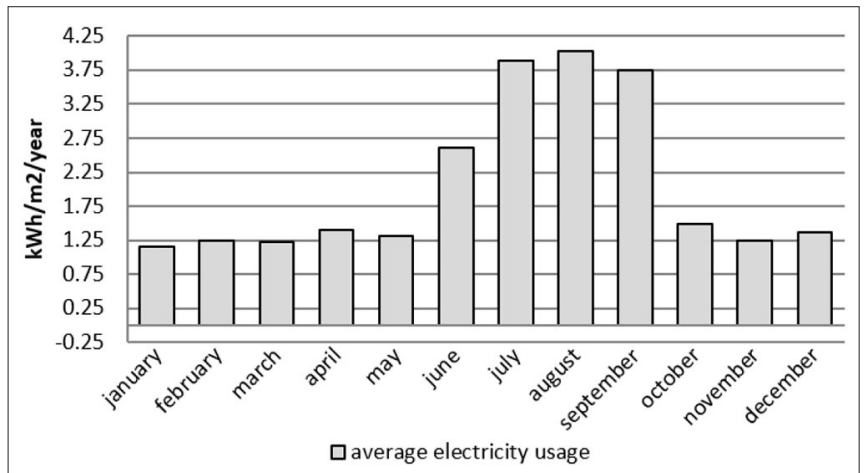

FIGURE 4 | The actual monthly average electricity consumption of the case study.

monthly average electricity consumption with a yearly average consumption of $26.6 \mathrm{kWh} / \mathrm{m}^{2}$ (Attia et al., 2012b).

\section{Occupancy Density and Behavior}

According to the established survey, the average apartment occupancy is about 4-5 persons per unit, with a plug loads average power intensity of $6 \mathrm{~W} / \mathrm{m} 2$. The survey also highlighted the occupancy daily patterns and lighting schedules for the airconditioned spaces, including the bedrooms and living areas for main seasons as shown in Figures 5, 6.

\section{RESULTS AND DISCUSSION}

The BIM to BEM process consists of a three-part BIM tool, model schema exchange format, and a BEM tool. Interoperability issues can arise from any of these parts and are not necessarily limited to the ability of BEM tools to read the input information. Regarding the first testing objective, following the data diagram for the Revit to BEM transition (Figure 7), all the tested data, as mentioned in the methodology and as per the ideal workflow of energy performance simulations (Figure 2), were determined and included in the Revit model. Then, the rooms were placed to create an analytical model, and from the analytical model the data regarding the Green Building XML (gbXML) were generated and loaded to DesignBuilder and IES-ve. However, the following settings were adjusted in order to control how this transition occurred.

The "settings-DesignBuilder" toolbar icon is found on the analysis menu of the Revit software. The general tab was kept as the default. The merge tab allows for any settings that might have been added during previous work to be retained when using the model within DesignBuilder; therefore, this was unchecked, otherwise it might open the transferred file and merge it with a previous DesignBuilder file. However, the merge settings can be useful if one has to work on Revit again after the transfer to DesignBuilder; in this case, one can check the "merge with existing model" options on the DesignBuilder settings dialogue to ensure that the previous DesignBuilder settings, if ok, are automatically installed with the new merged file. Finally, the Revit export tab allows for some control over the Revit end of the transition process. The use room/space volumes were selected, including complexity with mullions and shading surface, to generate the gbXML file.

On the other hand, the IES Revit plug-in appeared under the Add-Ins tab of Revit. According to the IES-ve manual, the performance analysis can be carried out at any time during the building design phase, however, the earlier it is conducted the more this will benefit the final stage. Therefore, based on the best practice instructions in the manual, for a better simulation analysis, the physical model needs some preparation including zone creation which will change the model into an analytical model, this can be done in Revit using the room and area settings to place the rooms and the spaces, in addition to all the other investigated parameters before transferring the model to IES-ve via the gbXML format. Once the file is ready to be transferred, in the settings menu, the unit has to be identified in addition to the quality of the exporting gbXML file. However, since the IES-ve Revit plug-in only works with an older version of Revit, and this might affect the results, the gbXML file was imported directly to IES-ve 2019 which allowed us to create the model from the BIM file option on the start-up page and select geometry plus all data.

\section{Description of Interoperability Issues}

\section{(a) Location and weather file}

Identifying the exact location and weather file is the most crucial step for accurate energy simulation, and this explains why it comes first in the ideal workflow of energy performance simulation (Figure 2). The interoperability issue is to examine the data transfer integrity of the location and weather file identified earlier in Revit before being exported to DesignBuilder and IES-ve. In the first trial, with the file operating in DesignBuilder, the location and weather files were different than indicated in Revit, and even the building type was different. Therefore, a second trial was undertaken, and this time the pre-exported settings for the gbXML file went through a slight modification by deselecting the "merge with existing file" option under the merge tab. Then, the file location, including longitude, 

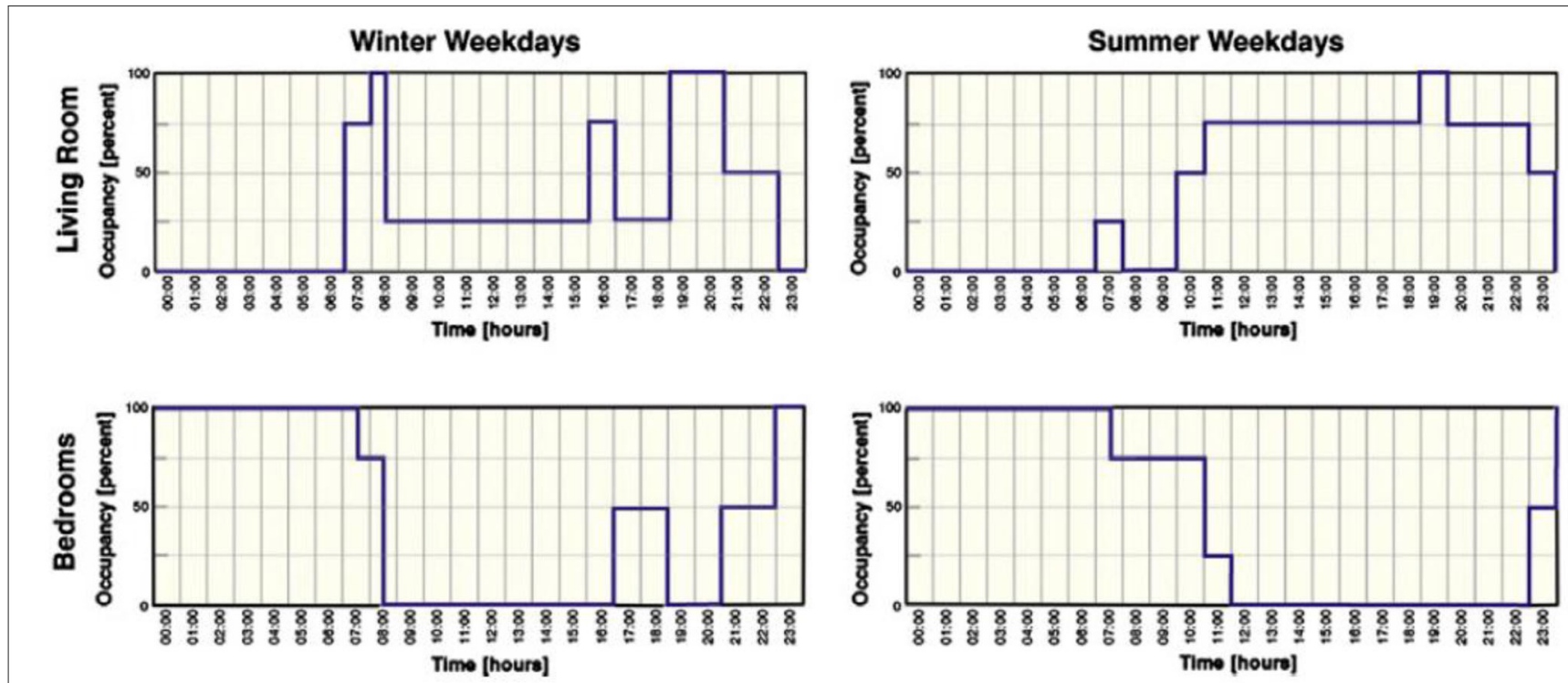

FIGURE 5 | The occupancy schedules (average) of the case study.
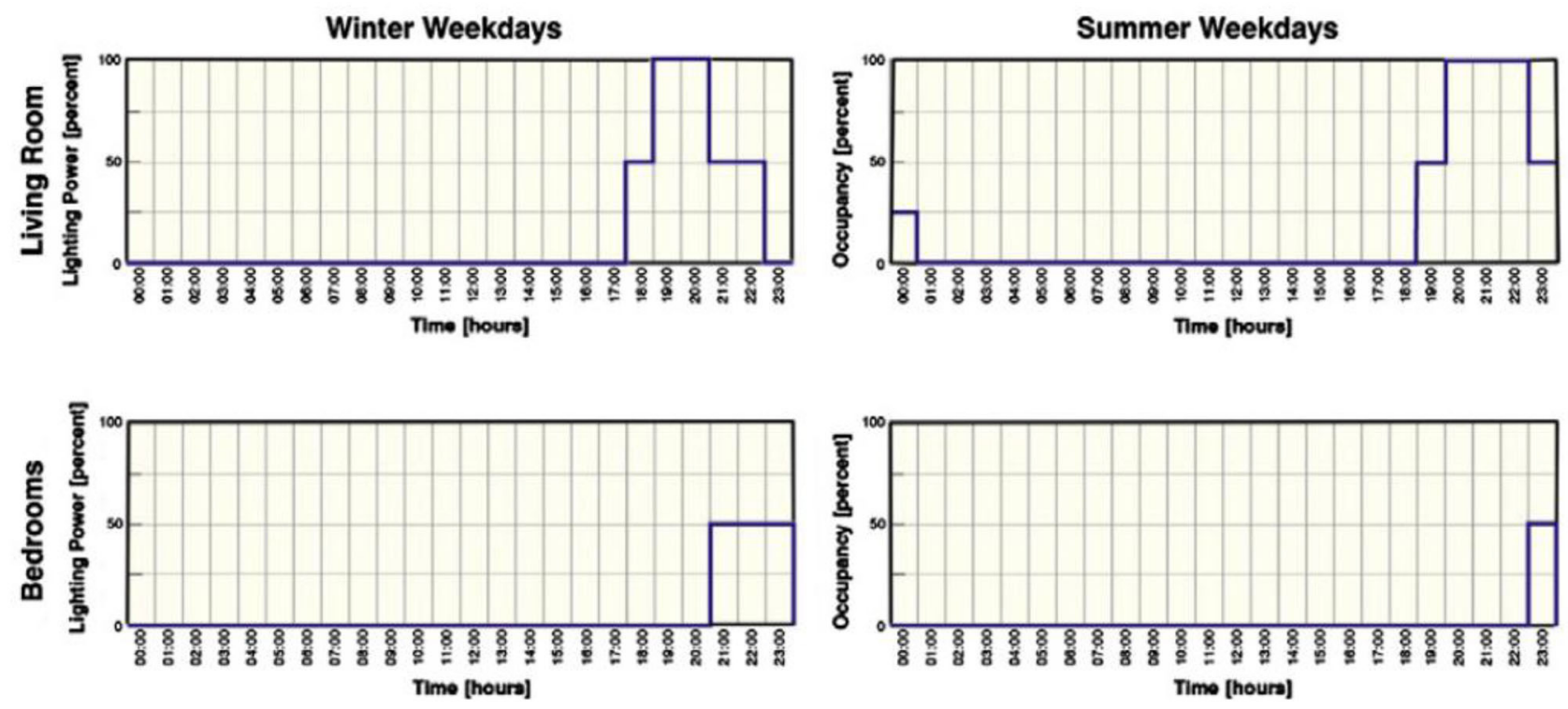

FIGURE 6 | The lighting schedules (average) of the case study.

latitude, and orientation, in addition to the weather file (acquired from Cairo airport weather station), were all transferred to DesignBuilder exactly as identified in Revit using the TMY format (typical meteorological year). However, it was noticed that the building type still needed to be re-identified in DesignBuilder. On the other hand, IES-ve smoothly recognized the location and weather file for the case study from the first upload.

\section{(b) Geometry}

The building geometry and form is also a crucial step, after the location and climate, as per the ideal workflow of energy performance simulation, and so it was essential to assess the transfer process of the geometric properties of the building model. However, so far there are no guidelines or recommendations for any method to verify the geometric data or form, other than the received message in BEM which includes the number of buildings, blocks, and zones identified after being transferred to DesignBuilder (Figure 8). Therefore, the geometry was visually inspected and the total heights of the building and each floor, as well as some room dimensions, were investigated. Occasionally these results and this approach are not accurate especially if the model is too complex, therefore, after the 


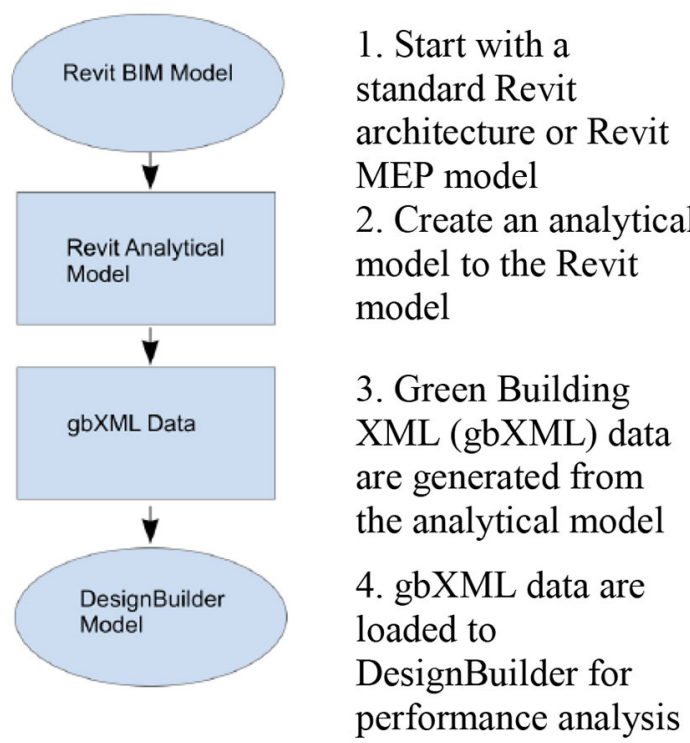

FIGURE 7 | Data diagram for the Revit to DesignBuilder transition (DesignBuilder Revit-gbXML Tutorial, 2019).

visual inspection, the gbXML file went through a model viewer known as Aragog, which is certified by Green Building XML. The model checker provides information regarding any missing data, entities, and reports related to geometry, weather files, and materials which help in rectifying the errors in the initial stages of transferring data as presented in Figure 9. The building geometry was exported successfully without any geometric errors, as the area was the same for each floor, and the number of doors and windows were well-preserved. One contrast found was that Revit identified the external walls as one structure starting from the ground level until $1 \mathrm{~m}$ above the roof slab, but in DesignBuilder the walls were separated based on the belonging spaces, and the roof parapet was considered as a shading surface.

With reference to the IES-ve, the geometry was successfully imported including the orientation as presented in Figure 10. Moreover, the IES-ve outperformed DesignBuilder, as it allows for previewing the BIM model before being imported and it generates an informative report, after the data were imported from the BIM, outlining some essential import feedback representing the area and volume of each room or space, highlighting any errors that occurred as a result of the intersections between the different surfaces. Although the geometry was successfully received by IES-ve, by comparing the volumes of the rooms between the IES-ve and Revit reports, there were slight differences in the room volumes where IES-ve had $10 \%$ more volume in what was actually specified in Revit which with a large project would certainly affect the energy consumption calculations. This difference in volume is due to the uncommon approach of calculating the area and volume between Revit and IES-ve, the Revit calculation is based on the internal distance between the walls while the IES-ve calculates the area based on the center lines of the walls. Again, similar to what occurred with DesignBuilder regarding the roof parapet, the
IES-ve considers these elements as local shadings as well, and the reason behind this conflict is that these elements do not have a proper classification in BIM unlike other spaces.

For further investigation, some modifications have only been applied to the building shape to investigate the BEM application capabilities in receiving more complex geometrical free forms including curves and circular shapes, via the gbXML format either through plug-ins or direct import into the programs, as shown in Figure 10. As shown in Figure 11, DesignBuilder did not recognize some materials on the curved boarder of the building instead considering them as shading devices and when analyzing the circular room at the end of the building DesignBuilder did not recognize the roof parapet or the curtain wall as a construction material for half of the circular shape (Figure 12). For the IES-ve, the scenario was worse as the software did not recognize the right shapes of some elements which were located on the curve line or the circular room, some walls were distorted and misshapen, while others were only recognized as shading devices without any materials and the circular room only had two floors with curtain walls while the others did not (Figure 13). The results were not surprising, it has been reported previously in some studies that the gbXML format will so far only accept rectangular shapes (Gourlis and Kovacic, 2017; Gao et al., 2019). Yet, it is still the best choice when it comes to energy simulation compared to the other available formats such as IFC (Osello et al., 2011; Gao et al., 2019).

\section{(c) Construction and materials}

Construction materials are the main factor responsible for the energy balance of the building envelope and the overall energy modeling. Accordingly, walls, windows, and doors, as representatives of the building envelope, were investigated based on three levels of data transfer, including the number and order of the building envelope layers and their thermal property values. The first investigated item was the number of layers and order of the exterior walls. Although all the construction layers, as shown in Figure 14, were successfully transferred into both BEM programs, DesignBuilder and IES-ve, to comply with the study objectives, more construction layers were added to create a more complicated building envelope for the sake of a more intensive investigation. Accordingly, the first discrepancy noted was the inability of DesignBuilder to transfer any type of layer with zero thickness, such as the membrane in Revit; in DesignBuilder, any layer without thickness would in turn have an insignificant thermal resistance value.

IES-ve successfully imported all the construction materials as a whole including the $U$-value and $R$-value as assigned in Revit without recognizing the different layers for each type. For instance, the external wall is a basic wall of $125 \mathrm{~mm}$ bricks with two plastering layers $20 \mathrm{~mm}$ each as the outer and inner finish on both sides with a total wall thickness of $165 \mathrm{~mm}$, IES-ve only recognized the whole wall as one unit equal to $165 \mathrm{~mm}$ including all the assigned thermal values in Revit without recognizing the layers.

The second discrepancy was related to the window types, despite being previously specified in the transfer settings; the degree of complexity should have included 


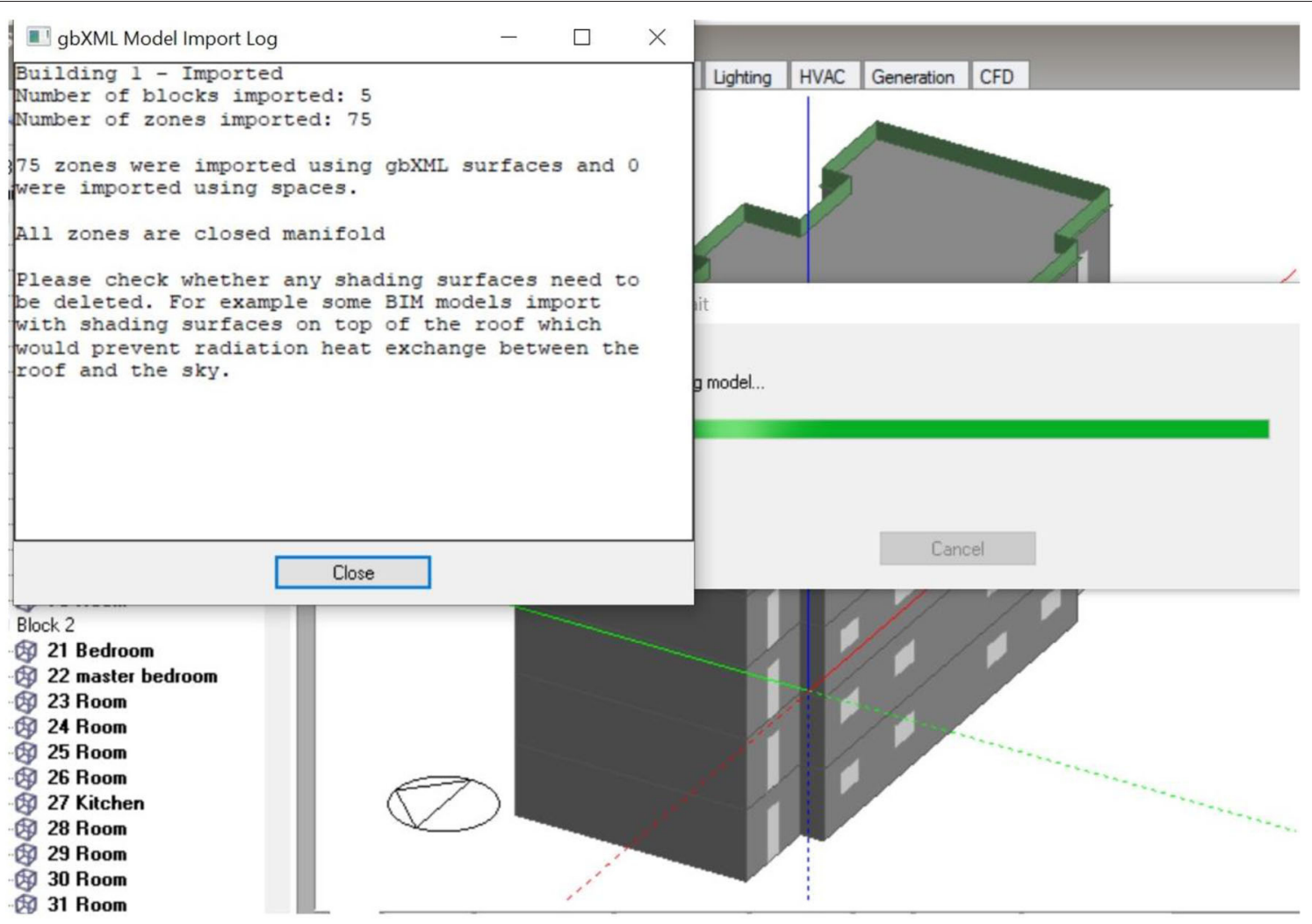

FIGURE 8 | DesignBuilder notification, including the number of buildings, blocks, and zones identified after the transfer.

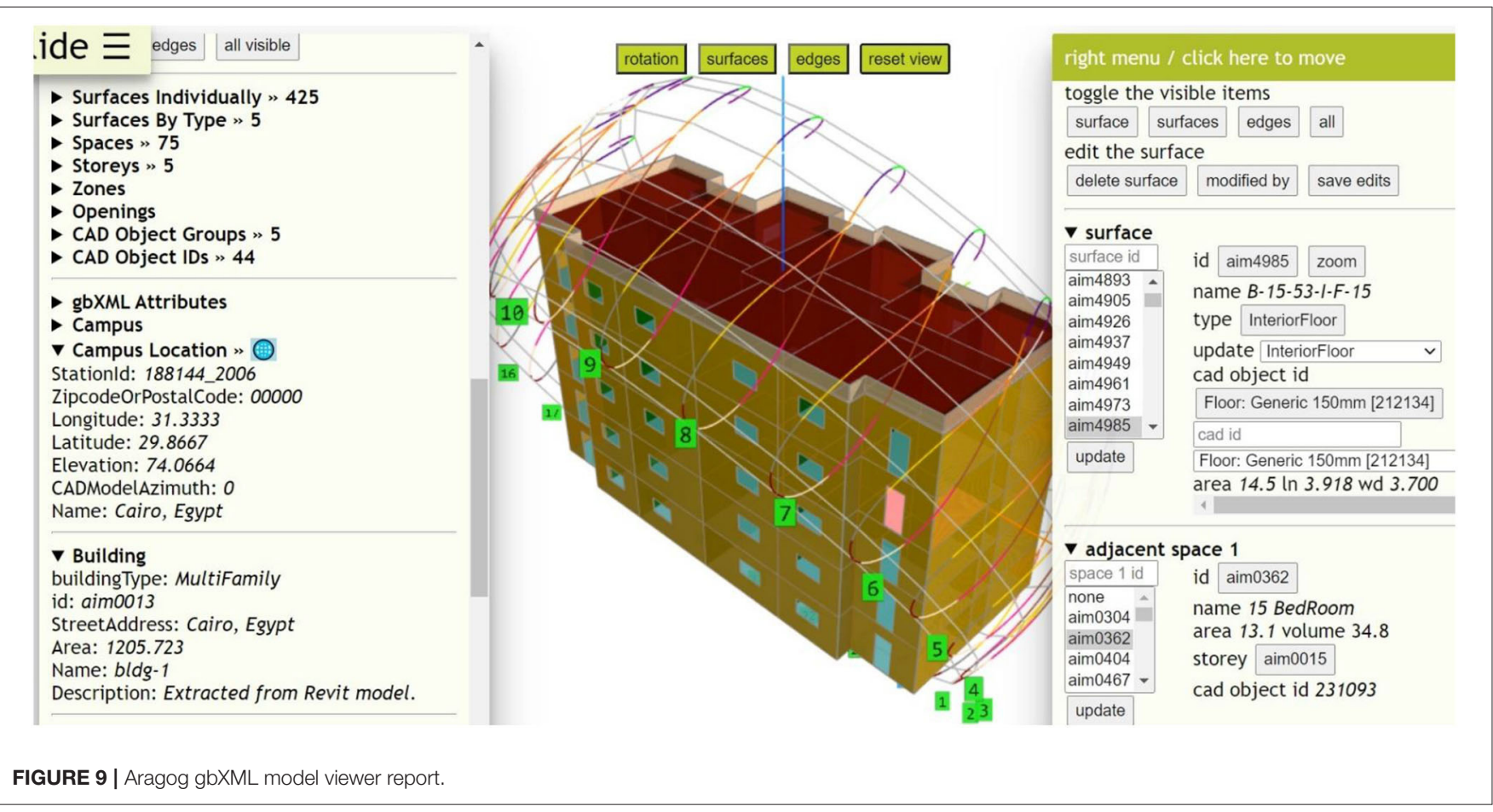




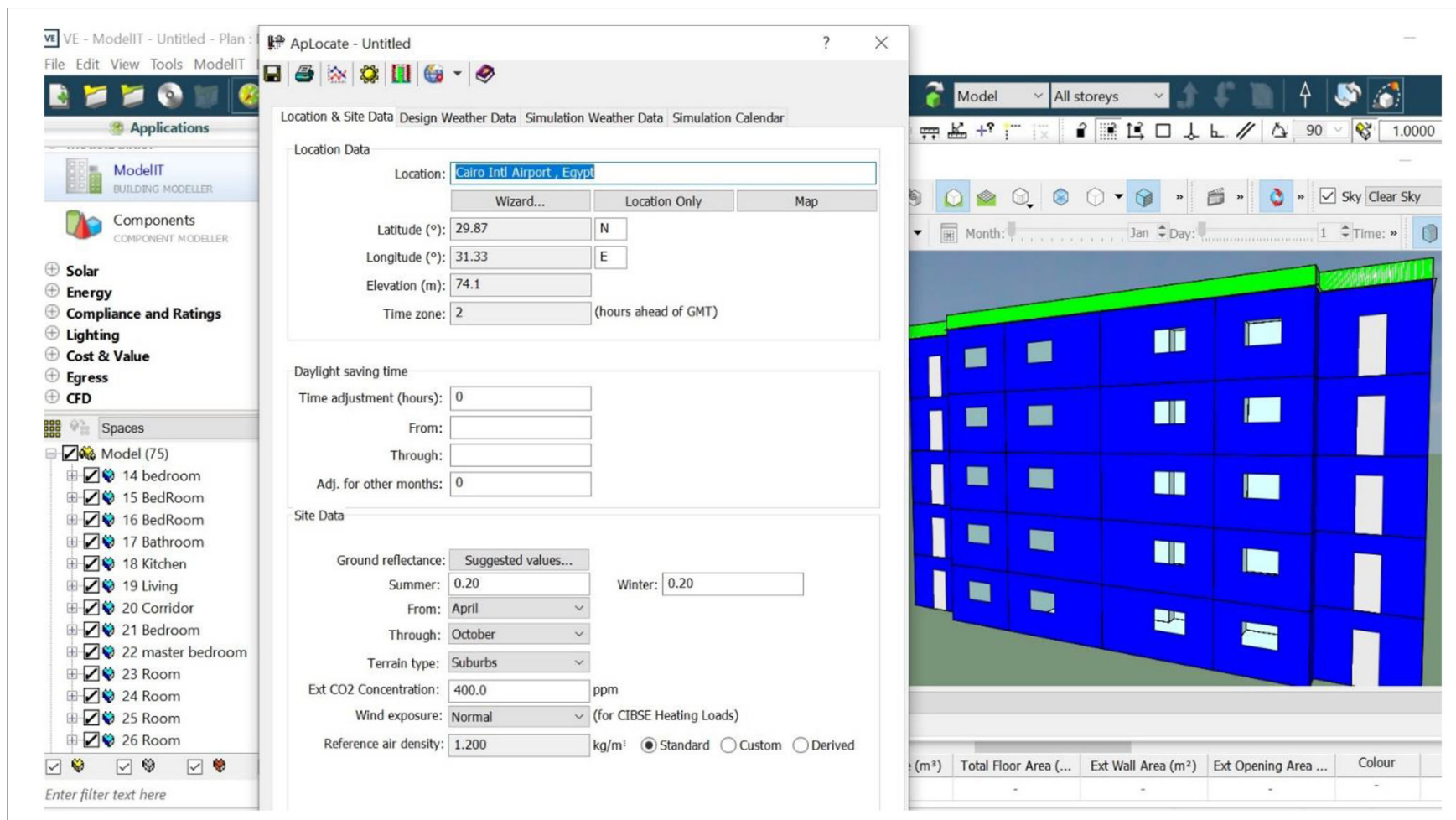

FIGURE 10 | IES-ve interface after successfully identifying the geometry file received from Revit including the weather file and spaces names.

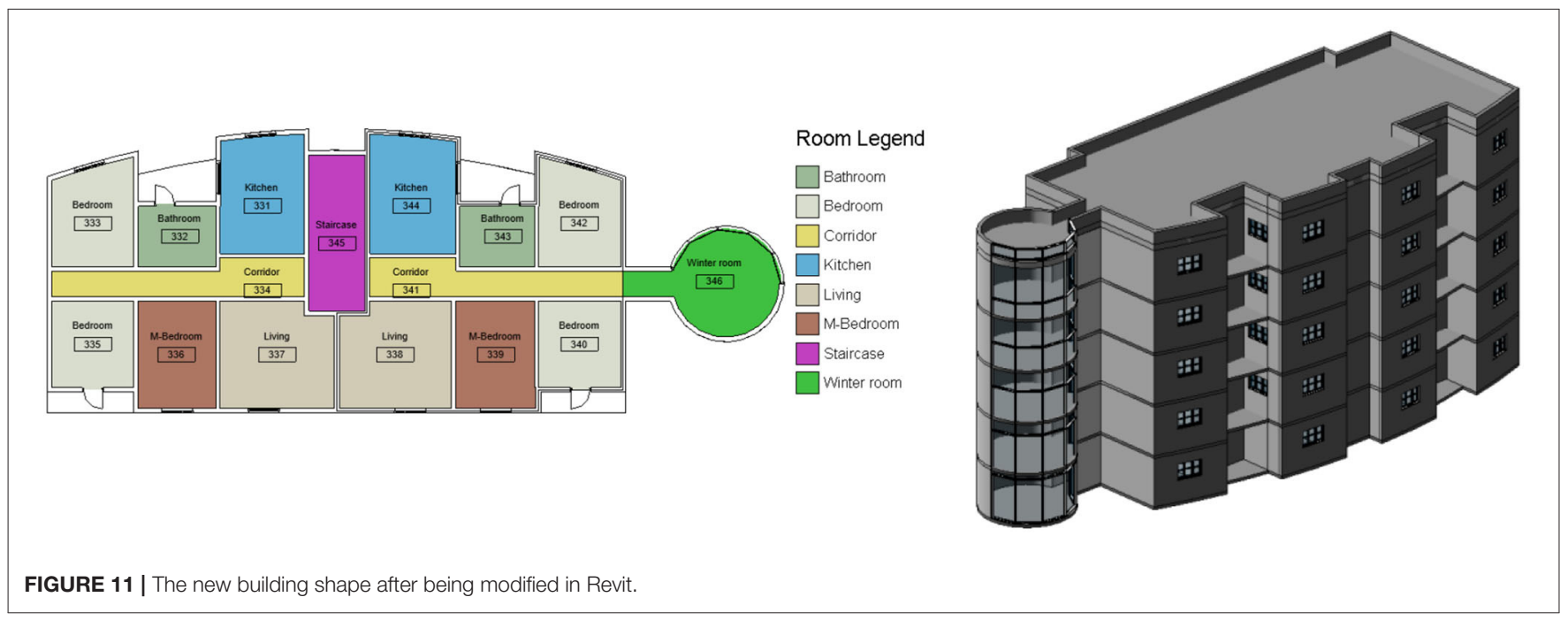

the mullions and shading surfaces in generating the two gbXML files, but the transferred data were missing the window materials and thermal properties in DesignBuilder and IES-ve. Therefore, the window materials and thermal properties were re-identified within the two programs. This was in contrast to the thermal properties of the doors, which were only successfully transferred and identified in DesignBuilder.

\section{(d) Thermal zones}

According to the DesignBuilder tutorial, the generation of an analytical model for energy can only be performed if all the areas are defined by the room components in the building model, and the entire volume of the building model is included. In Revit, the terms of the zones, spaces and rooms are independent, and each term has a different function. Zones and spaces are used to determine the heating and cooling loads and the thermal 
energy calculation of the building, while rooms are used as a building component which retains the architectural data of the occupied areas. Therefore, all the areas were identified as rooms, spaces, and zones in Revit. On the DesignBuilder transfer "settings" toolbar, the Revit export tab has two options for applying the analytical model (AM) for the room use/space volumes, which were selected to ensure the smooth transfer of the rooms and spaces between the two programs. Overall, all rooms were successfully exported in DesignBuilder based on comparing the number of created spaces in both programs, in addition to the room volume. The only discrepancy was that some rooms, after being transferred, had different names to the ones created in Revit, and therefore all the room names were reviewed and renamed to match with the original file created in Revit (Figure 15). The same settings were applied for the IES-ve imported file; all the spaces have been transferred successfully yet

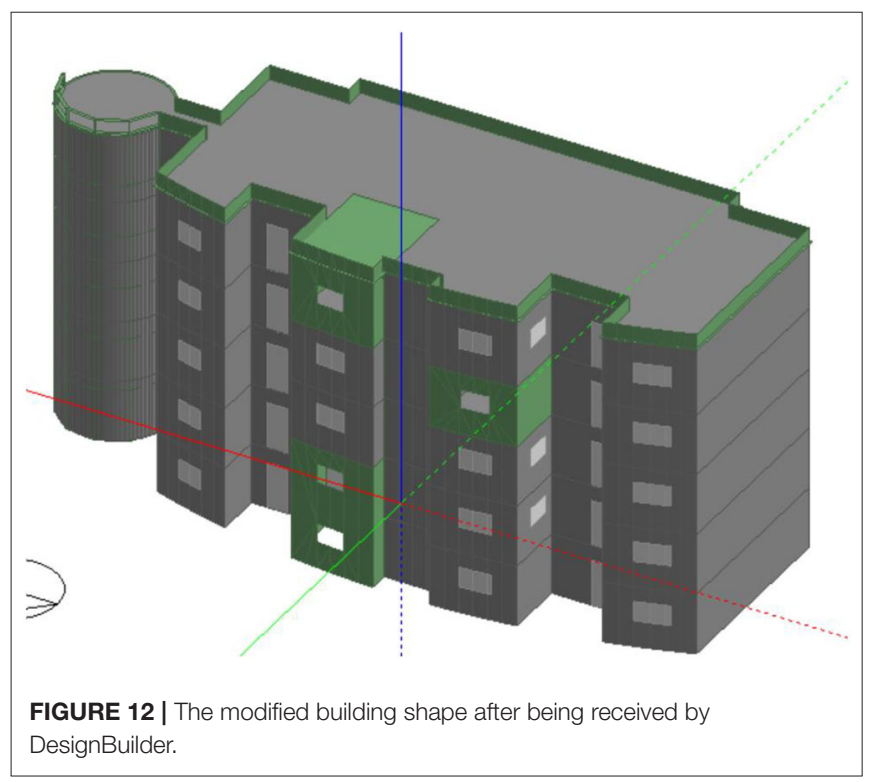

there was some inconsistency between the space names identified by IES-ve with the original file created in Revit (Figure 15), in addition to the $10 \%$ increase in the volume as mentioned earlier under the geometry section.

\section{(e) Occupancy operating schedule}

The occupancy schedule was set according to the multifamily building type. In Revit, these assumptions are default based on the building type, so there are no other possible options than selecting the operating schedule from the drop-down menu. However, if the spaces were used as the export category in the energy settings, then under the space properties in the energy analysis section, the operating schedule settings can be customized for each space based on its function, including the

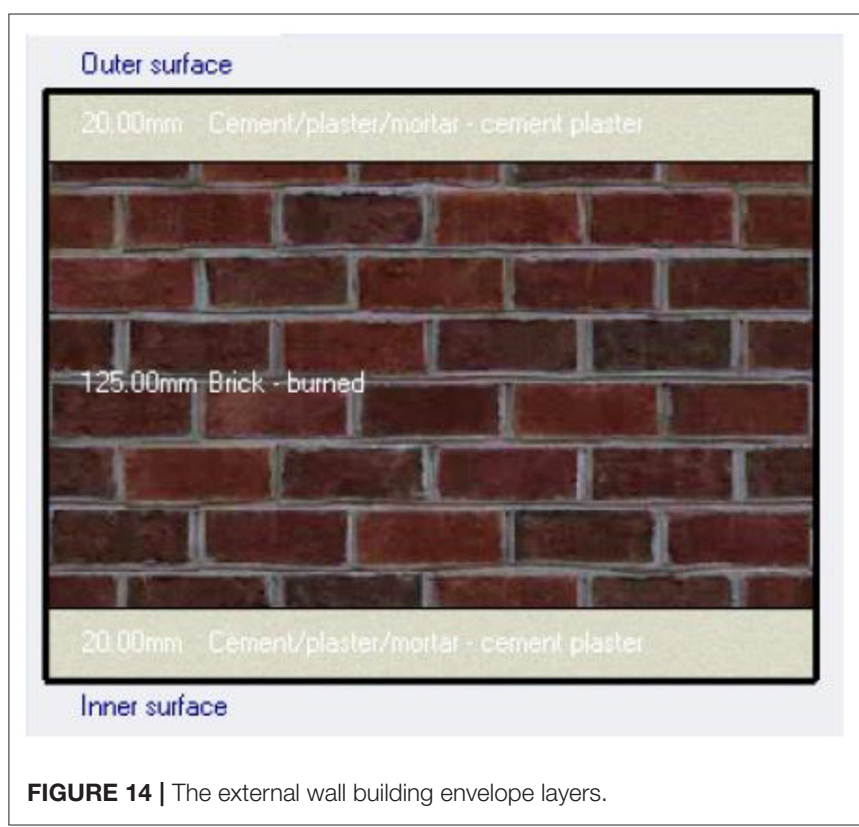

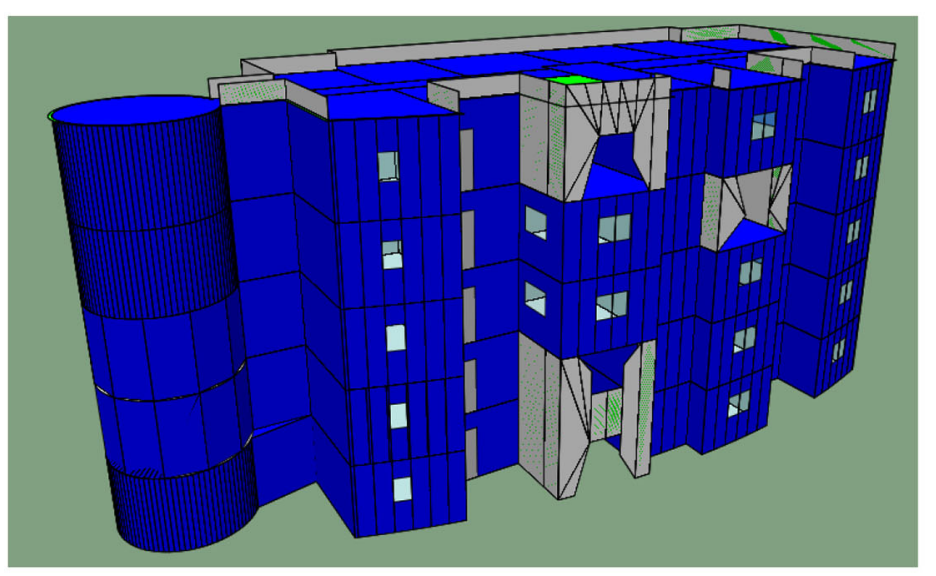

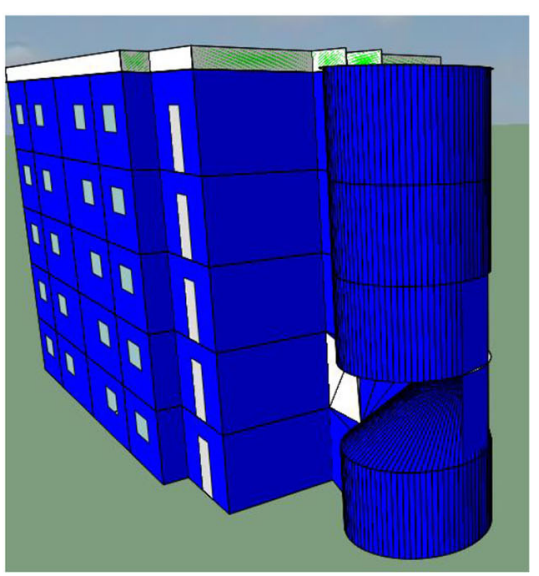

FIGURE 13 | The modified building shape after being received by IES-ve. 

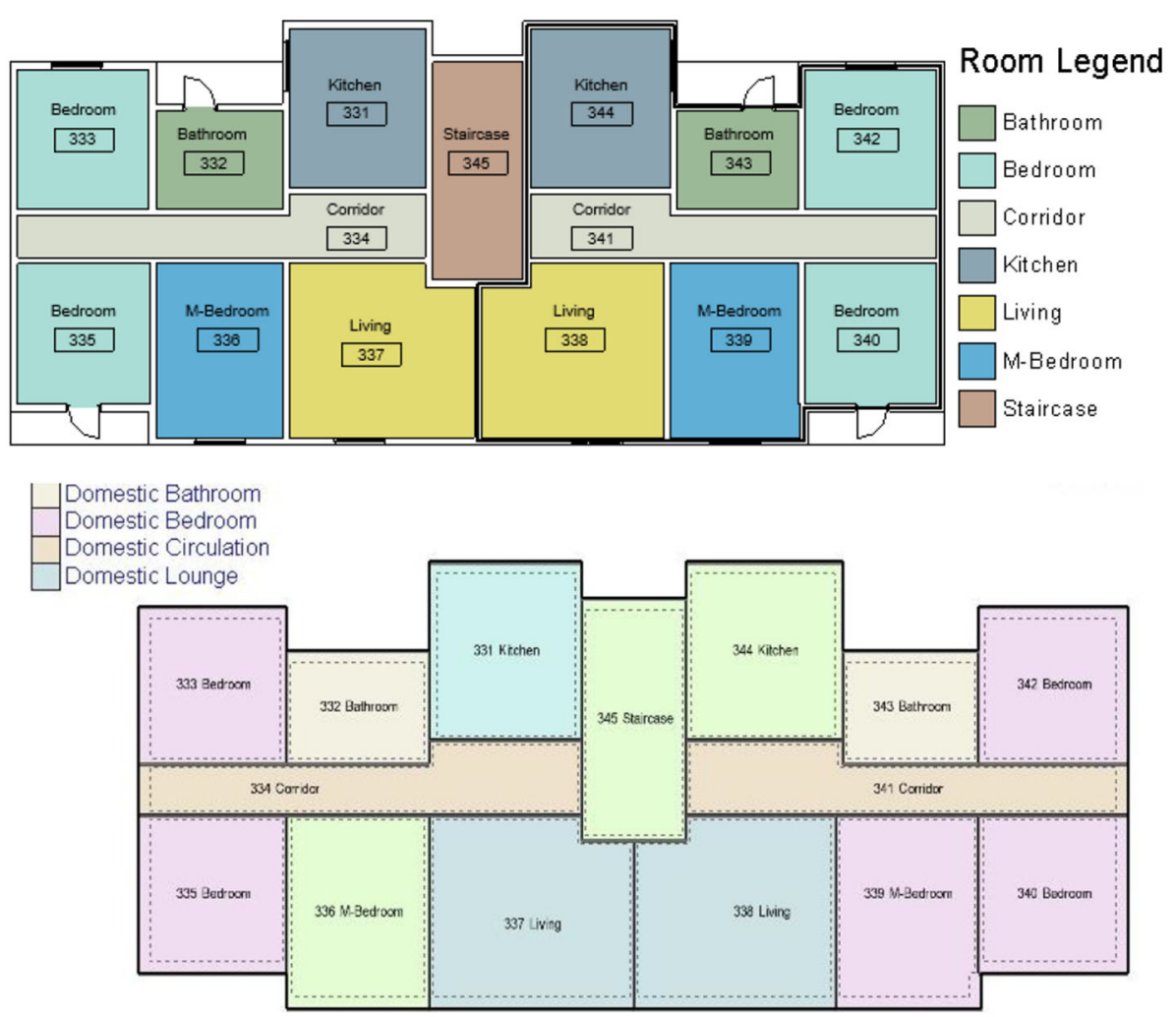

FIGURE 15 | Spaces and zones identification in Revit (left hand-side) and DesignBuilder (right hand-side).

occupancy, lighting, and power schedule (Figure 16). Therefore, the data were customized and exported for DesignBuilder and IES-ve, which could not maintain the data transfer integrity and started to use their own template to overwrite the imported data. Accordingly, all the data regarding the occupancy operating schedule were re-assigned in DesignBuilder and IES-ve as per the surveyed data and as shown in Figure 6 and Table 3. DesignBuilder and IES-ve allow more flexibility for users to design their own operating schedule than Revit, which applies any customized operational schedule for the whole year without allowing the user to differentiate between seasons or weekdays, and in turn this affects the energy analysis results.

\section{(f) HVAC systems}

Revit has a very limited list of HVAC systems, and does not allow more than one HVAC system for each building, which in turn does not serve the different types as per the actual survey where eighty percent of the apartments in the sample had air conditioners (split or window units), serving mainly bedrooms and/or living rooms. Nevertheless, this might be adequate for the early stage of the design analysis regarding the overall energy consumption for different iterations. Therefore, the model was set to export by space in the energy setting dialogue, which allows DesignBuilder to perform energy analysis based on specific settings made in each space. Although the data chosen from the Revit drop-down menu were very limited,
DesignBuilder did not recognize the imported data. On the other hand, IES-ve, reassigned all the energy data according to its HVAC library based on the imported space type. For instance, multifamily space type, as identified in Revit, was assigned under the predesigned patterns that exist in the IES-ve library such as internal gains including multifamily lighting, multifamily occupants, and multifamily equipment. IES-ve verified and reassigned the imported spaces based on its type and whether it matched the type in the IES-ve library, despite the fact that the type of information that accompanied this choice led to the false transition of data. Thus, in order to serve the second aim of the study regarding the validity of the BIM-based BEM model, to obtain an energy performance test on the BIM-based model, all the data regarding the HVAC system had to be adjusted within DesignBuilder and IES-ve, as shown in Table 4.

\section{Energy Performance Test Using the BIM-Based Model}

Additionally, one of the key challenges of BEM tools is to test the accuracy of the representation of the actual energy performance of the building and reduce the discrepancies between the modeling energy outcomes and the actual measured data (Hong et al., 2018). Following the European Standard EN 15.603 (DS/EN, 2008) validation procedures for energy modeling, the simulated results were compared against the actual energy consumption of the case study, using dynamic 


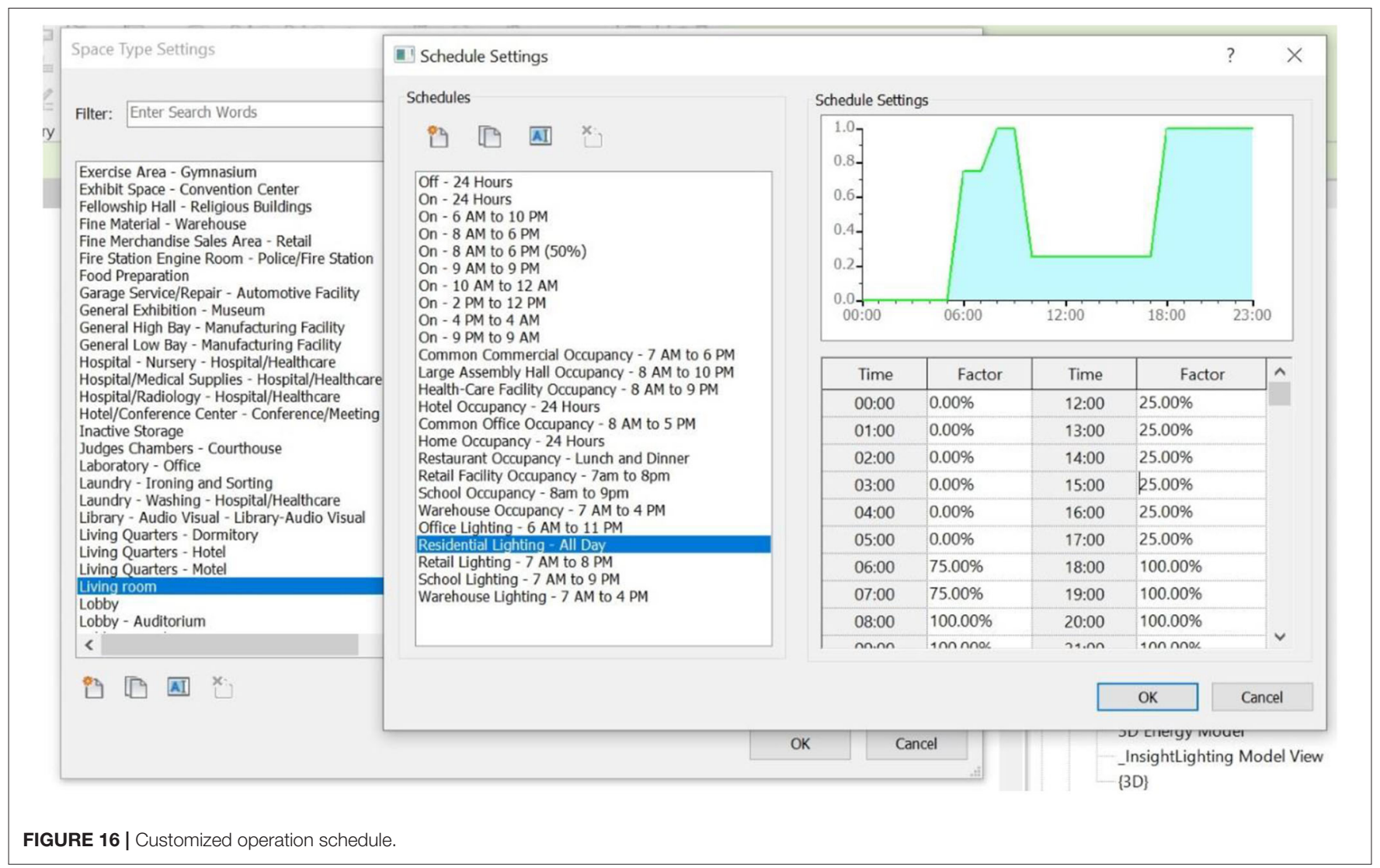

TABLE 4 | Building HVAC system and lighting description.

Ventilation and air conditioning

COP/EER

Outside air ( $\mathrm{m}^{3} / \mathrm{h}$ per person)

Temperature set point (_C)-adaptive

Relative humidity set point (\%)-adaptive

Lighting

Installation power density $\left(\mathrm{W} / \mathrm{m}^{2}\right)$ : living rooms

Installation power density $\left(\mathrm{W} / \mathrm{m}^{2}\right)$ : bedrooms

Installation power density $\left(\mathrm{W} / \mathrm{m}^{2}\right)$ : other

Visible trans (VLT)

methods for calculating the energy balance and modeling the heat transmission through the building envelope, losses or gains due to ventilation and solar heat gains in each space within the building (std. EN ISO 13790:2008). Due to the nature of the study, using two different BEM applications where each model might use a different approach based on various modeling assumptions and input data which impact the software application's capabilities. As most of the BEM tools come under two main groups, the first are applications using energyplus which is one of the most developed set of building simulation algorithm engines developed by the US Department of Energy (DOE), such as DesignBuilder, while the other group use their own calculation engines, such as IES-ve (Dong et al., 2007). Therefore, the accuracy of the energy simulation is determined by the ability of the input data to accurately represent the case study. The input data mainly consists of the building geometry, internal loads, HVAC systems and components, weather data, operating strategies and schedules, and simulation specific parameters, all of which have been described earlier under the modeling approach and settings section. In this regard, an energy simulation was performed to verify the accuracy of DesignBuilder and IES-ve in dealing with all the input data received from Revit such as the geometry, location, and weather file, as well as all other parameters which revealed some discrepancies during the data exchange process and had to be reassigned using the BEM applications such as the construction materials, thermal zones, HVAC, and occupant operation schedule. The actual energy consumption obtained from the billing history of the local electricity utility company is benchmarked against the energy modeling results generated from DesignBuilder and IES-ve in Figure 17. The modeled energy for both programs performed a reliable approximation with the observed data. DesignBuilder simulated data were very similar to the actual ones, and yet the shape shifted slightly toward the lower limits compared to the case study reported data, with a deviation of $0.8 \%$. While the shape composed by IES-ve slightly shifted to the upper limits, with a deviation of $0.93 \%$, this might be due to the $10 \%$ increase in the space volume compared to the original BIM model. Still, both BEM application outcomes were strongly correlated to the 
TABLE 5 | Summary of overall interoperability issues between Revit and BEM tools.

\begin{tabular}{|c|c|c|}
\hline Revit 2019 & DesignBuilder v6 & IES-ve 2019 \\
\hline Plugin & $\begin{array}{l}\text { - The plug-in worked effectively and saved time by } \\
\text { directly transferring the file from Revit using the gbXML } \\
\text { format and automatically opening DesignBuilder }\end{array}$ & $\begin{array}{l}\text { - The plug-in was only available for older versions of } \\
\text { Revit, however the new IES-ve provided an easy } \\
\text { process to export BIM using the gbXML format } \\
\text { automatically under the BIM file option on the } \\
\text { start-up page }\end{array}$ \\
\hline Location and weather file & $\begin{array}{l}\text { - Site location and coordinates are properly imported } \\
\text { from the BIM file including the weather file }\end{array}$ & $\begin{array}{l}\text { - Site location and coordinates are properly imported } \\
\text { from the BIM file including the weather file }\end{array}$ \\
\hline Geometry & $\begin{array}{l}\text { - Geometry and orientation of the building were } \\
\text { successfully imported. However, the software did not } \\
\text { provide detailed guidelines or recommendations for } \\
\text { any method to verify the geometric data or form } \\
\text { - The model failed to preserve the circular or free } \\
\text { geometric information of the building }\end{array}$ & $\begin{array}{l}\text { - Geometry and orientation of the building were } \\
\text { successfully imported with detailed reports for each } \\
\text { space and volume conditions with more options to fix } \\
\text { any errors } \\
\text { - The model created a } 10 \% \text { increase in the space volume } \\
\text { compared to the original BIM file } \\
\text { - The model failed to preserve the circular or free } \\
\text { geometric information of the building }\end{array}$ \\
\hline Construction and materials & $\begin{array}{l}\text { - The construction layers were successfully transferred. } \\
\text { However, DesignBuilder was unable to transfer any } \\
\text { type of layer with zero thickness } \\
\text { - The window construction materials were not } \\
\text { successfully imported }\end{array}$ & $\begin{array}{l}\text { - Only construction type name and the U-values of each } \\
\text { construction type were imported successfully without } \\
\text { identifying the different layers individually } \\
\text { - The windows and doors construction material and } \\
\text { thermal properties could not be imported }\end{array}$ \\
\hline Thermal zones & $\begin{array}{l}\text { - All rooms successfully exported into DesignBuilder, in } \\
\text { addition to the room volume } \\
\text { - The only discrepancy was that some rooms, after } \\
\text { being transferred, had different names compared to } \\
\text { the ones created in Revit }\end{array}$ & $\begin{array}{l}\text { - All the spaces were transferred successfully yet there } \\
\text { was some inconsistency between the space names } \\
\text { identified by IES-ve with the original file } \\
\text { - In addition to the } 10 \% \text { increase in the space volume }\end{array}$ \\
\hline Occupancy operating schedule & $\begin{array}{l}\text { - DesignBuilder could not maintain the data transfer } \\
\text { integrity and started to use its own template to } \\
\text { overwrite the imported data }\end{array}$ & $\begin{array}{l}\text { - IES-ve could not maintain the data transfer integrity } \\
\text { and started to use its own template to overwrite the } \\
\text { imported data }\end{array}$ \\
\hline HVAC systems & $\begin{array}{l}\text { - DesignBuilder did not recognize the imported HVAC } \\
\text { data }\end{array}$ & $\begin{array}{l}\text { - IES-ve reassigned all the energy data according to its } \\
\text { HVAC library based on the imported space type despite } \\
\text { the fact that the type of information accompanied with } \\
\text { this choice led to the false transition of data } \\
\text { - All the data had to be reassigned in IES-ve }\end{array}$ \\
\hline
\end{tabular}

measured ones and within an acceptable range of deviation since the percentage of differences was $<10-20 \%$ (Maamari et al., 2006; Oleiwi et al., 2019). Both programs have been tested and validated by ANSI/ASHRAE Standard 140-2011 for building thermal envelope calculation and Fabric Load, in addition to the TM33 test for energy performance in the UK. However, any discrepancies between the measured and simulated energy consumption is heavily related to uncontrolled human behavior. It is very common for occupants to open windows in an attempt to adjust the temperature in residential buildings which causes an extra load for the heating and cooling system and affects the heat gain or loss in the building (Andersen et al., 2013; D'Oca and Hong, 2014). The same applies for the occupancy, lighting, and power schedule patterns but has a lesser significant effect on energy consumption.

\section{CONCLUSION}

There is an increasing need to apply building information modeling (BIM) to low energy buildings, this includes building energy modeling (BEM). The seamless data exchange between different platforms for creating a BIM-based BEM model will provide better collaboration within the architecture, engineering, and construction (AEC) industries, yet it is still not a common practice. One of the major arguments behind this is the lack of recent studies which link the practical side of data handover between the most widely used programs. Hence, this paper presents a line-by-line analysis of data handover integrity, following the ideal workflow for BEM tools, recommended by Maile et al. (2007), including the main interoperability topics as suggested by Bahar et al. (2013) and discussed by Gao et al. (2019), such as: the location and weather file, geometry, construction and materials, thermal zones, occupancy operating schedule, and HVAC systems. The data transition between Revit and DesignBuilder and IES-ve concealed a number of interoperability issues regarding the BIM data input and BEM data interpretation (Table 5). The key findings of the analysis presented herein can be concluded as follows:

- The spatial and geometric data were received and interpreted successfully from Revit as BIM to either DesignBuilder or IES-ve as the two BEM software applications and with a high degree of accuracy. However, there are no guidelines or recommended techniques available to allow the modeler to validate the accuracy of the geometric data transfer, rather 


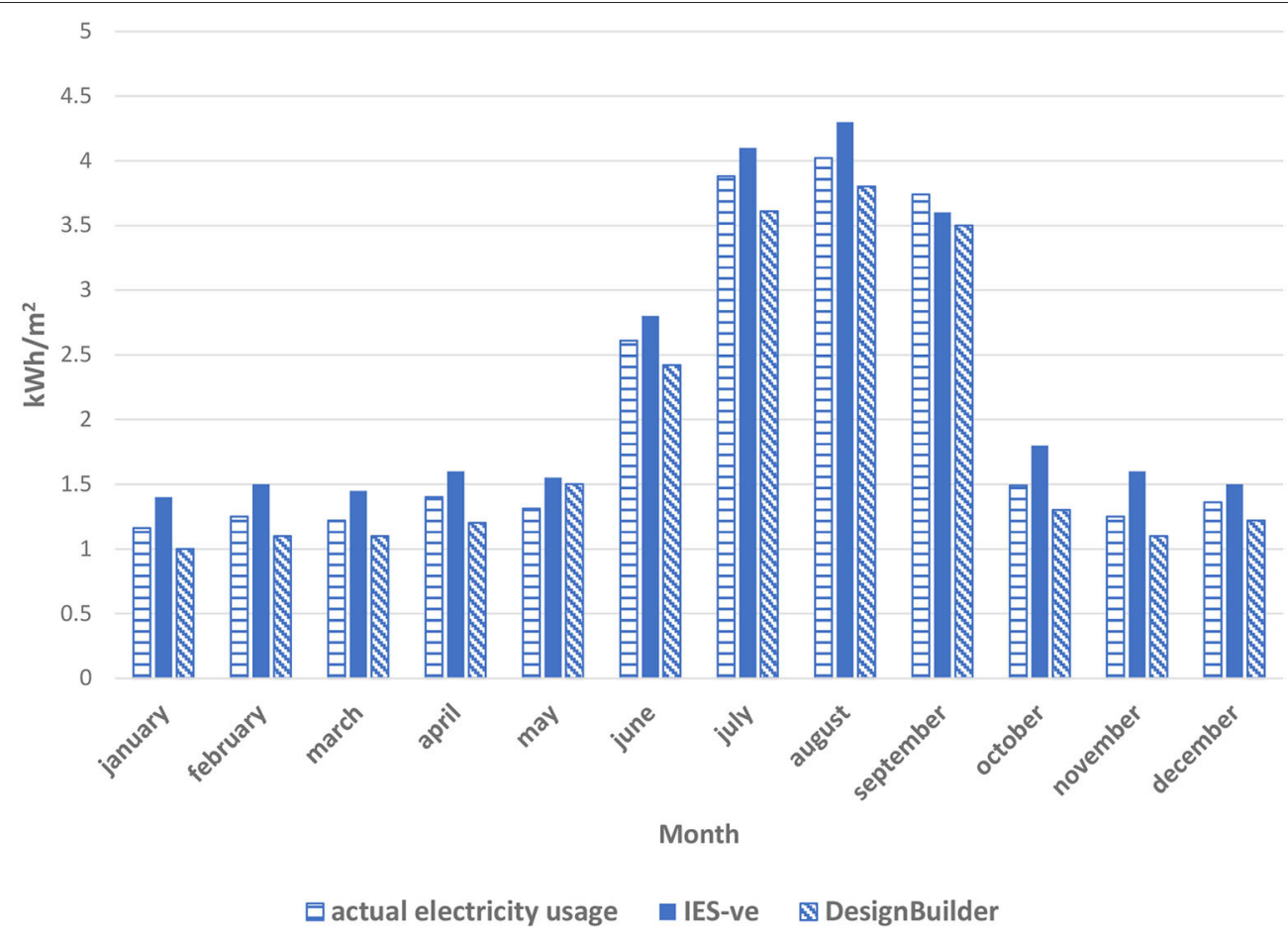

FIGURE 17 | Simulated and actual monthly electricity usage.

than the received notification in DesignBuilder identifying the number of buildings, blocks, and zones. Rather, it is up to each user to apply a different strategy, such as visual inspection, or their own techniques, therefore the file went through an Aragog model checker as certified by Green Building XML to verify the model before being imported to DesignBuilder to rectify any errors in this initial stage. On the other hand, IES-ve provides a preview for the BIM model before importing which allows the user to fix the geometry from any occurred error followed by a detailed report regarding each volume and space.

- DesignBuilder received the gbXML file which contained less information regarding the non-geometric data, such as the spaces and rooms, and although all were transferred in the right quantity, DesignBuilder re-identified them with different names, and the function of each room had to be re-identified again by the modeler. While IES-ve successfully identified the received space types as assigned in the BIM model from Revit, but it did not recognize some of the preassigned names in the original BIM file in addition to a $10 \%$ increase in the space volume compared to the original BIM model. The construction materials, including the thermal properties, were generally correctly transferred for both BEM software applications. However, DesignBuilder could not identify any type of layer with zero thickness (e.g., membrane in Revit). While IES-ve did not recognize the different layers of the construction materials, as it dealt with the materials as one unit with a total $U$-value and $R$-value despite how many construction layers it contained. Moreover, the exported files were missing the thermal properties of the windows, as identified previously in Revit, although the thermal properties of the doors were only successfully identified by DesignBuilder.

- The occupancy schedule in Revit (BIM) is based on a previously assigned assumption according to the building type selected. While this was customized under the space properties in the energy analysis section, including the occupancy, lighting, and power schedule, these data were misrepresented or overwritten during the process of data transfer to both the BEM software applications, DesignBuilder and IES-ve (BEM). The occupancy operating schedule had to be re-assigned in the two BEM programs which allows more flexibility than Revit, so that the modelers could customize their own schedule, which, in turn, affect the energy analysis results.

- The HVAC systems are very limited in Revit as they only allow one HVAC system for the whole building, which might be acceptable for early design stages. Despite the very limited data assigned in Revit, the transferred data were misrepresented in DesignBuilder, while IES-ve tried to assign different types of HVAC based on the type assigned by Revit for each space using data from the IES-ve library. Therefore, all the data conducted from the survey regarding the case study had to be assigned again in DesignBuilder and IES-ve to cope with the study objective of validating the energy analysis outcomes.

- The two BIM-based model simulation outputs were very close to the actual measured data, they were all within the acceptable range of $<10-20 \%$ (Maamari et al., 2006; Oleiwi et al., 2019). 
Yet still the day-by-day and hourly data should be analyzed to investigate the accuracy and preference of the software for future research.

According to the above-mentioned findings, it can be declared that both DesignBuilder and IES-ve are very similar to each other in terms of data interpretation, however, the data exchange between these two BEM software applications and Revit is still not as efficient as expected and each has its own limitations. Both BEM applications succeeded in importing the building geometry, location, and weather file, yet still faced some deficiencies in importing some data related to the construction details such as missing the thermal properties of the windows or not identifying some construction layers. The same applies for occupancy operating schedule and HVAC. Although these items might seem like a BEM limitation, actually, the tested BEM applications provide users with more flexibility to identify and create their own operation schedule pattern and their HVAC system especially when these two items vary from one building to another and even from one space to another. If there is some limitations regarding these two interoperability issues, the shortage will be in the BIM application represented in Revit, where the operating schedule is based on the building type with no other customized option for the users to design their own schedule, while for the HVAC, Revit only allows one HVAC system for the whole building, without providing any other options such as a mixed HVAC system which is widely used today in different types of buildings.

In conclusion, BIM-based BEM models might be a very reliable tool for sustainable and low energy building design in the near future, yet the BIM to BEM process is a nonstandardized practice that produces building energy models which vary from one user to another and from one application to another. And are still not applicable for every phase of

\section{REFERENCES}

AEC (2013). AECbytes Newsletter \#62 Aconex Survey. Available online at: http://www.aecbytes.com/newsletter/2013/issue_62.html (accessed February 28, 2013).

Andersen, R., Fabi, V., Toftum, J., Corgnati, S. P., and Olesen, B. W. (2013). Window opening behaviour modelled from measurements in Danish dwellings, Build. Environ. 69(Suppl. C), 101-113. doi: 10.1016/j.buildenv.2013.07.005

Attia, S., Evrard, A., and Gratia, E. (2012b). Development of benchmark models for the Egyptian residential buildings sector. Applied Energy 94, 270-284. doi: 10.1016/j.apenergy.2012.01.065

Attia, S., Hensen, J. L., Beltran, L., and De Herde, A. (2012a). Selection criteria for building performance simulation tools: contrasting architects and engineers needs. J. Build. Perform. Simul. 5, 155-169. doi: 10.1080/19401493.2010.549573

Attia, S. G. M., and Herde, A. D. (2009). Bioclimatic architecture: design strategies in Egypt. Aachen, Germany. Sustainable Energy Technol. 1, 1-17.

Bahar, Y. N., Pere, C., Landrieu, J., and Nicolle, C. (2013). A thermal simulation tool for building and its interoperability through the Building Information Modelling (BIM) platform. Buildings. 3, 380-398. doi: 10.3390/buildings3020380

Bazjanac, V. (2008). IFC BIM-Based Methodology for Semi-Automated Building Energy Performance Simulation. Berkeley, CA. Available online at: https:// digital.library.unt.edu/ark:/67531/metadc897563/ (accessed November 19, 2020). the building life cycle. Therefore, it is crucial to differentiate the capabilities of these two approaches. Revit (BIM) does not provide many options for customization, such as the operation schedule or HVAC, which might be a very helpful tool for early design analysis to support decisions such as building form, mass, orientation, and fenestration. On the other hand, DesignBuilder and IES-ve (BEM) may be the best options for a validated energy analysis at the later phases of the project life cycle. Additionally, the data flow between the two programs tends to be one-way regardless of the types of formatting being used, which means any modification in BEM cannot be recognized in the BIM model. These limitations hinder the process and prevent many professionals in the field from applying this integration. In closing, it is worth noting that the main method of reaching the objective of synchronizing the BIM to BEM interoperability is still a long way ahead. Some of the investigated issues in this paper still need to be addressed in the future, this paper only investigated one building type using single file formatting for data exchange, and there were some areas which still needed manual intervention at some points within the process. All these areas still need further investigation and open the door for future studies.

\section{DATA AVAILABILITY STATEMENT}

The raw data supporting the conclusions of this article will be made available by the authors, without undue reservation.

\section{AUTHOR CONTRIBUTIONS}

The author confirms being the sole contributor of this work and has approved it for publication.

Bazjanac, V. (2018). "Virtual Building Environments - Applying Information Modelling to Buildings," in European Conference on Product and Process Modeling in the Building and Construction Industry (ECPPM) 2004 (Istanbul, Berkeley, CA: Lawrence Berkeley National Lab).

Bertin, I., Mesnil, R., Jean-Marc, J., Feraille, A., and Le Roy, R. (2020). A BIMbased framework and databank for reusing load-bearing structural elements. Sustainability. 12:3147. doi: 10.3390/su12083147

BIEG (2020). BIM Interoperability Expert Group (BIEG) Report. Construction Innovation HUB. Available online at: https://www.cdbb.cam.ac.uk/files/cih_ bim_interoperability_expert_group_report_april_2020_final_wm_removed. pdf

BuildingSMART (2016). BIM Guides Project. BuildingSMART. Available online at: http://bimguides.vtreem.com/bin/view/Main/

Bynum, P., Issa, R. R. A., and Olbina, S. (2013). Building information modelling in support of sustainable design and construction. J. Constr. Eng. Manag. 139, 24-34. doi: 10.1061/(ASCE)CO.1943-7862.0000560

Cemesova, A. (2013). Enhancing BIM-Based Data Transfer to Support the Design of Low Energy Buildings. Cardiff: Cardiff University.

Cemesova, A., Hopfe, C. J., Mcleod, R. S. (2015). Passive- BIM: enhancing interoperability between BIM and low energy design software. Autom. Constr. 57, 17-32. doi: 10.1016/j.autcon.2015.04.014

Ceranic, B., Latham, D., and Dean, A. (2015). Sustainable design and building information modelling: case study of energy plus house, Hieron's Wood Derbyshire UK. Energy Procedia 83, 434-443. doi: 10.1016/j.egypro.2015.12.163 
Chen, C.-J., Chen, S.-Y., Li, S.-H., and Chiu, H.-T. (2017). Green BIM-based building energy performance analysis. Comput. Aided Design Appl. 14, 650-660. doi: $10.1080 / 16864360.2016 .1273582$

Chen, S., Jin, R., and Alam, M. (2018). Investigation of interoperability between building information modelling (bim) and building energy simulation (bes). Int. Rev. Appl. Sci. Eng. 9, 137-144. doi: 10.1556/1848.20 18.9.2.9

Cheng, J. C. P., and Das, M. (2014). A BIM-based web service framework for green building energy simulation and code checking. J. Inform. Technol. Constr. 19, 150-168. Available online at: https://www.itcon.org/2014/8

DesignBuilder Revit-gbXML Tutorial (2019). Design Builder Revit-gbXML Tutorial. Available online at: https://www.designbuilder.co.uk/; https:// designbuilder.co.uk/downloads/db_revit_tutorial_v1.pdf (accessed May 22, 2020).

D'Oca, S., and Hong, T. (2014). A data-mining approach to discover patterns of window opening and closing behavior in offices. Build. Environ. 82, 726-739. doi: 10.1016/j.buildenv.2014.10.021

Dong, B., Lam, K. P., Huang, Y. C., and Dobbs, G. M. (2007). "A comparative study of the IFC and gbXML informational infrastructures for data exchange in computational design support environments geometry information," in Proceeding of Building Simulation (Syracuse, NY: Syracuse Univ), 1530-1537.

DS/EN (2008). DS/EN 15603: Energy Performance of Buildings - Overall Energy Use and Definition of Energy Ratings. Charlottenlund. Available online at: https:// webshop.ds.dk/en-gb/standard/ds-en-156032008?CurrencyCode=EUR

Dubois, M. C., and Horvat, M. (2012). State-of-the-Art of Digital Tools Used by Architects for Solar Design. Paris: IEA SHC, 22-115.

Eastman, C., Teicholz, P., Sacks, R., Liston, K. (2008). BIM Handbook: A Guide to Building Information Modelling. New Jersey: John Wiley \& Sons. doi: $10.1002 / 9780470261309$

El Asmi, E., Robert, S., Haas, B. and Zreik, K. (2015), A standardized approach to BIM and energy simulation connection. Int. J. Design Sci. Technol. 21, 59-82. Available online at: https://hal-cea.archives-ouvertes.fr/cea- 01847290

Elnabawi, M., and Hamza, N. (2019). Investigating Building Information Model (BIM) to Building Energy Simulation (BES): interoperability and simulation results. Earth Environ. Sci. 397. doi: 10.1088/1755-1315/397/1/0 12013

Fernald, H., Hong, S., O'Brien, L., and Bucking, S. (2018) BIM to BEM Translation Workflows and Their Challenges: A Case Study Using a Detailed BIM Model. IBSPA, Montréal, QC.

Forth, K., Braun, A., and Borrmann, A. (2019). "BIM-integrated LCA - model analysis and implementation for practice," in Proceedings of the SBE D-A-CH 19 IOP Conf. Ser, (Bristol, Graz: IOP Science).

Gao, H., Christian, K., Yupeng, W. (2019). Building information modelling based building energy modelling: a review. Appl. Energy. 238, 320-343. doi: 10.1016/j.apenergy.2019.01.032

Garcia, E. G., and Zhu, Z. (2015). Interoperability from building design to building energy modelling. J. Build. Eng. 1, 33-41. doi: 10.1016/j.jobe.2015. 03.001

Gourlis, G., and Kovacic, I. (2017). Building information modelling for analysis of energy efficient industrial buildings - a case study. Renew. Sustain. Energy Rev. 68, 953-963. doi: 10.1016/j.rser.2016.02.009

Gratia, E., and De Herde, A. (2002). A simple design tool for the thermal study of an office building. Energy Build. 34, 279-289. doi: 10.1016/S0378-7788(01)00096-2

Han, T., Huang, Q., Zhang, A., and Zhang, Q. (2018). Simulationbased decision support tools in the early design stages of a green building-a review. Sustainability 10, 1-23. doi: 10.3390/su1010 3696

Hitchcock, R. J., and Wong, J. (2011). "Transforming IFC architectural view BIMs for energy simulation: 2011," in Proceedings of Building Simulation 2011: 12th Conference of International Building Performance Simulation Association (Sydney, NSW), 1089-1095

Hong, T., Langevin, J., Sun, K. (2018). Building simulation: ten challenges. Build. Simul. 11, 871-898. doi: 10.1007/s12273-018-0444-x

IBC (2013). Digicon/IBC 2013 National BIM Survey Analysis. Available online at: https://www.ibc-bim.ca/wp-content/uploads/2014/10/Digicon-IBC_ SurveyAnalysis.pdf
IBPSA (2019). Building Energy Software Tools - Best Directory. International Building Performance Simulation Association. Available online at: https:// www.buildingenergysoftwaretools.com/home?page $=1$ (accessed April 01, 2019).

IEA (2019). Global Energy \& CO2 Status Report 2019, Paris: IEA. Available online at: https://www.iea.org/reports/global-energy-co2-status-report-2019

IES VE (2011). VE Module Tutorial. Available online at: http://www.iesve.com/ software/download-trial (accessed October 17, 2011).

Jin, R., Zhong, B., Ma, L., Hashemi, A., and Ding, L. (2019). Integrating BIM with building performance analysis in project life-cycle. Autom. Constr. 106:102861. doi: 10.1016/j.autcon.2019.102861

Kamel, E., and Memari, A. (2019). Review of BIM's application in energy simulation: tools, issues, and solutions. Autom. Constr. 97, 164-180. doi: 10.1016/j.autcon.2018.11.008

Kim, J. B., Jeong, W. S., Clayton, M. J., Haberl, J. S., and Yan, W. (2015). Developing a physical BIM library for building thermal energy simulation. Autom. Constr. (2015) 50, 16-28. doi: 10.1016/j.autcon.2014.10.011

Kota, S., Haberl, J. S., Clayton, M. J., Yan, W. (2014). Building Information Modelling (BIM)-based daylighting simulation and analysis. Energy Build. 81, 391-403. doi: 10.1016/j.enbuild.2014.06.043

Kumar, S. (2008). Interoperability Between Building Information Models (BIM) and Energy Analysis Programs. University of Southern California, Los Angeles, CA.

Kurul, E., Abanda, H., Tah, J. H., and Cheung, F. (2013). "Rethinking the build process for BIM adoption," in CIB World Building Congress Construction and Society (Brisbane, QLD).

Laine, T., Hänninen, R., and Karola, A. (2007). "Benefits of BIM in the thermal performance management," in Proceedings of the Building Simulation (Beijing), $1455-1461$.

Leaman, A., Thomas, L., and Vandenberg, M. (2007). "Green” Buildings: What Australian users are saying. EcoLibrium, 22-30.

Maamari, F., Andersen, M., de Boer, J., Carroll, W., Dumortier, D., and Greenup, P. (2006). Experimental validation of simulation methods for bi-directional transmission properties at the daylighting performance level. Energy Build. 38, 878-889. doi: 10.1016/j.enbuild.2006. 03.008

Maile, T., Fischer, M., and Bazjanac, V. (2007). "Building energy performance simulation tools-a life-cycle and interoperable perspective," in CIFE Working Paper 107, 1-49.

Moon, H. J., Choi, M. S., Kim, S. K., and Ryu, S. H. (2011). "Case studies for the evaluation of interoperability between a BIM-based Architectural model and building performance analysis program," in Proceedings of Building Simulation 2011: 12th conference of International Building Performance Simulation Association (Sydney, NSW), 14-16.

NBS (2014). NBS National BIM Report 2014. Newcastle Upon Tyne: National Building Specification (NBS). Available online at: https://www.thenbs.com/ knowledge/nbs-national-bim-report-2014

NBS (2016). National BIM Report 2016. Newcastle Upon Tyne: National Building Specification (NBS). Available online at: https://www.thenbs.com/knowledge/ national-bim-report-2016

Oleiwi, M. Q., Mohamed, M. F., Sulaiman, M. K. A. M., Che-Ani, A. I., and Raman, S. N. (2019). Thermal environment accuracy investigation of integrated environmental solutions-virtual environment (IES-VE) software for double-story house simulation in malaysia. J. Eng. Appl. Sci. 14, 3659-3665. doi: $10.36478 /$ jeasci.2019.3659.3665

Osello, A., Cangialosi, G., Dalmasso, D., Di Paolo, A., Turco, M. L., Piumatti, P., et al. (2011) "Architecture data and energy efficiency simulations: BIM and interoperability standards," in Proceedings of Building Simulation 2011: 12th conference of International Building Performance Simulation Association (Sydney, NSW), 2210-2217.

Ostergard, T., Jensen, R. L., and Maagaard, S. E. (2016). Building simulations supporting decision making in early design - a review. Renew. Sustain. Energy Rev. 61, 187-201. doi: 10.1016/j.rser.2016.03.045

Penttilä, H. (2006). Describing the changes in architectural information technology to understand design complexity and free-form architectural expression. J. Inform. Technol. Constr. 11, 395-408. Available online at: https://www.itcon. org/2006/29 
Ramaji, I. J., Messner J. I., and Mostavi, E. (2020). IFC-based BIM-to-BEM model transformation. J. Comput. Civil Eng. 34. doi: 10.1061/(ASCE)CP.1943-5487.0000880

Salmon, S. M. (2013). A Comparative Analysis of Energy Modelling Methods for Commercial Buildings. All Theses and Dissertations, 3703. Available online at: https://scholarsarchive.byu.edu/etd/3703

Sarvari, H., Chan, D. W. M., Rakhshanifar, M., Banaitiene, N., and Banaitis, A. (2020). Evaluating the impact of Building Information Modeling (BIM) on mass house building projects. Buildings 10:35. doi: 10.3390/buildings10020035

Shen, W., Hao, Q., Mak H., Neelamkavil, J., Xie, H., Dickinson, J., et al. (2010). Systems integration and collaboration in architecture, engineering, construction, and facilities management: a review. Adv. Eng. Inform. 24, 196-207. doi: 10.1016/j.aei.2009. 09.001

Solmaz, A. S. (2019). A Critical Review on Building Performance Simulation Tools. Alam Cipta, 12, Izmir.

Standard 90 Standards Coordinating Committee (1990). IEEE Standard Glossary of Software Engineering Terminology (IEEE Std 610.12-1990). New York, NY: The Institute of Electrical and Electronics Engineers.

Stumpf, A., Kim, H., and Jenicek, E. (2011). Early Design Energy Analysis Using Building Information Modelling Technology. Kansas City, MO: U.S.
Army Corps of Engineers Engineer Research and Development Center. doi: 10.21236/ADA552789

USGSA (2015). BIM Guide 05 - Energy Performance. Washington, DC: U.S. General Services Administration.

van Dijk, E. J., and Luscuere, P. G. (2002). An Architect Friendly Interface for a Dynamic Building Simulation Program. Oslo: Sustainable Building Norway. doi: 10.1088/1755-1315/323/1/012100

Won, J., and Cheng, J. C. P. (2017). Identifying potential opportunities of building information modeling for construction and demolition waste management and minimization. Autom. Constr. 79, 3-18. doi: 10.1016/j.autcon.2017.02.002

Conflict of Interest: The author declares that the research was conducted in the absence of any commercial or financial relationships that could be construed as a potential conflict of interest.

Copyright (c) 2020 Elnabawi. This is an open-access article distributed under the terms of the Creative Commons Attribution License (CC BY). The use, distribution or reproduction in other forums is permitted, provided the original author(s) and the copyright owner(s) are credited and that the original publication in this journal is cited, in accordance with accepted academic practice. No use, distribution or reproduction is permitted which does not comply with these terms. 